\title{
Carbon Nanodots: A Review-From the Current Understanding of the Fundamental Photophysics to the Full Control of the Optical Response
}

\author{
Alice Sciortino 1,2,3,*, Andrea Cannizzo ${ }^{3, *}$ and Fabrizio Messina ${ }^{1, *}$ \\ 1 Dipartimento di Fisica e Chimica, Università degli Studi di Palermo, Via Archirafi 36, 90123 Palermo, Italy \\ 2 Dipartimento di Fisica ed Astronomia, Università degli Studi di Catania, Via Santa Sofia 64, \\ 95123 Catania, Italy \\ 3 Institute of Applied Physics, University of Bern, Sidlerstrasse 5, CH-3012 Bern, Switzerland \\ * Correspondence: alicesciortino@gmail.com (A.S.); andrea.cannizzo@iap.unibe.ch (A.C.); \\ fabrizio.messina@unipa.it (F.M.)
}

Received: 6 November 2018; Accepted: 5 December 2018; Published: 13 December 2018

\begin{abstract}
Carbon dots (CDs) are an emerging family of nanosystems displaying a range of fascinating properties. Broadly speaking, they can be described as small, surface-functionalized carbonaceous nanoparticles characterized by an intense and tunable fluorescence, a marked sensitivity to the environment and a range of interesting photochemical properties. CDs are currently the subject of very intense research, motivated by their possible applications in many fields, including bioimaging, solar energy harvesting, nanosensing, light-emitting devices and photocatalyis. This review covers the latest advancements in the field of CDs, with a focus on the fundamental understanding of their key photophysical behaviour, which is still very debated. The photoluminescence mechanism, the origin of their peculiar fluorescence tunability, and their photo-chemical interactions with coupled systems are discussed in light of the latest developments in the field, such as the most recent results obtained by femtosecond time-resolved experiments, which have led to important steps forward in the fundamental understanding of CDs. The optical response of CDs appears to stem from a very complex interplay between the electronic states related to the core structure and those introduced by surface functionalization. In addition, the structure of CD energy levels and the electronic dynamics triggered by photo-excitation finely depend on the microscopic structure of any specific sub-type of CD. On the other hand, this remarkable variability makes CDs extremely versatile, a key benefit in view of their very wide range of applications.
\end{abstract}

Keywords: carbon dots; nanocarbon; fluorescence; photophysics; photochemistry; ultrafast; femtosecond

\section{Introduction}

Carbon nanodots (CDs), discovered in the mid-2000s [1,2], are one of the protagonists of carbon nanoscience. CDs are nanoparticles smaller than $\approx 10 \mathrm{~nm}$ (Figure 1 ) typically composed by carbon, oxygen, nitrogen and hydrogen. Their most important hallmark is a bright fluorescence, tunable across the visible range, which has revolutionized the traditional paradigm of carbon as a black material unable to emit light. Their luminescence is accompanied by many additional benefits, such as low cost, ease of synthesis, high water solubility, biocompatibility, non-toxicity, high sensitivity to the external environment, and marked electron donating and accepting capabilities. This combination of properties allows for using CDs in a very broad range of applications, across many different fields ranging from optoelectronics to sensing. In fact, the potential of CDs is evident from the explosion of the number of studies, currently ranging in the thousands per year. From the practical point of view, the optical properties of CDs are somehow comparable, and often competitive, to fluorescent semiconductor 
quantum dots (QDs). Compared to them, luminescent CDs are superior in terms of aqueous solubility, high resistance to photobleaching, low toxicity and good biocompatibility [3]. In addition, they do not usually show blinking effects [4], they display strong absorption in the blue and UV ranges, and their reported QYs are steadily increasing, due to the progressive improvement of the synthesis procedures.

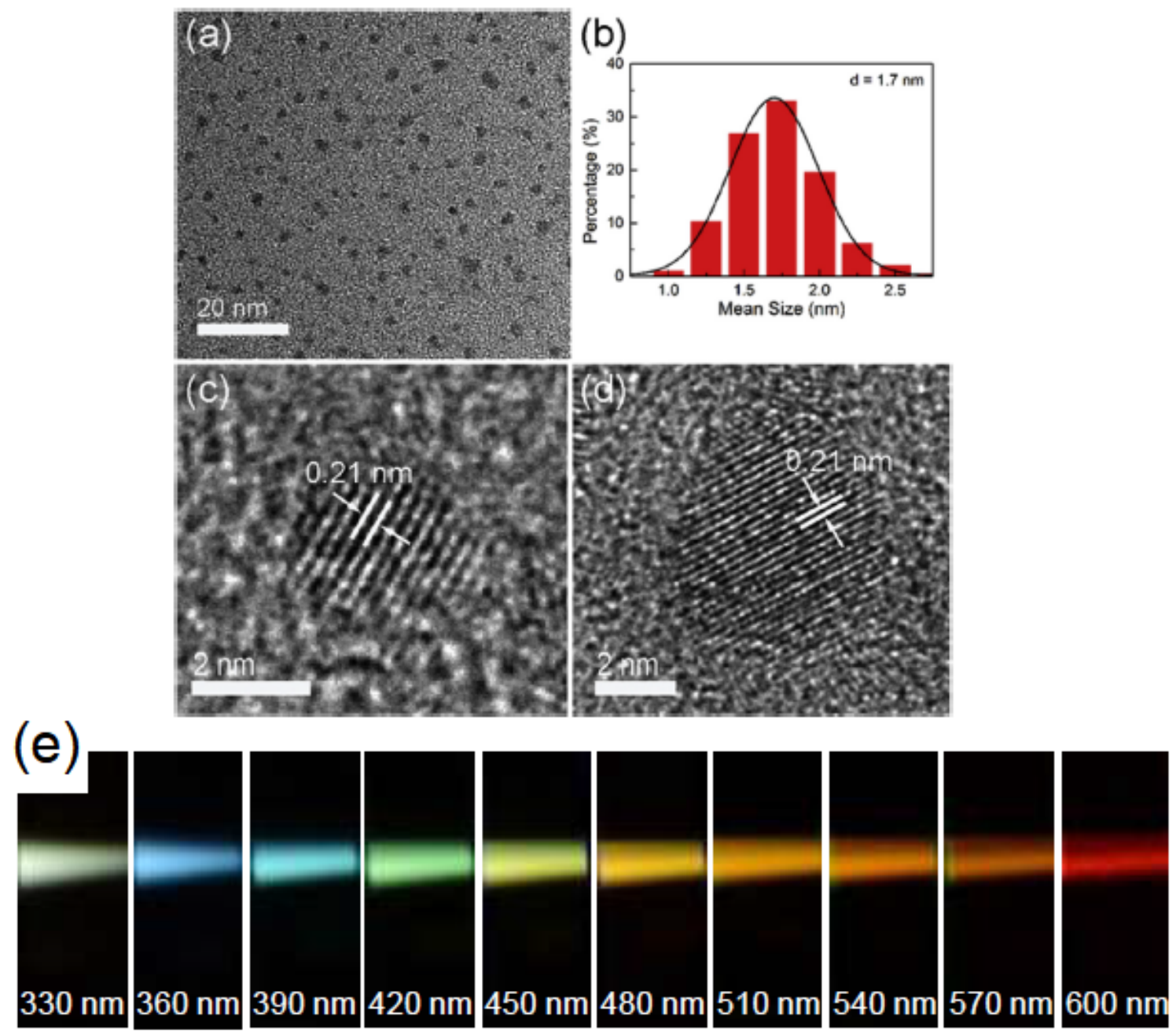

Figure 1. (a) transmission electron microscopy image of CDs; (b) size distribution of CDs; (c,d) examples of single crystalline CDs from (a). Reproduced with permission from [5]. Copyright Elsevier, 2016. (e) example of tunable fluorescence of CDs photographed during the photoexcitation at different wavelengths (indicated in figure). Reproduced with permission from [6]. Copyright John Wiley and Sons, 2015.

From a structural viewpoint, CDs are a relatively wide family of nanomaterials with a range of possible structures and variable optical properties. Their morphology is mostly quasi-spherical, and the structure can be graphitic [1], amorphous [7], or characterized by a $\mathrm{C}_{3} \mathrm{~N}_{4}$ crystalline core [8-10]. Even graphene quantum dots (GQDs), which can be pictured as nanometer-size fragments of monolayer graphene [11], may probably be considered a special sub-type of CDs because they display very similar photophysics despite the two-dimensional morphology. In all the synthesis approaches, the surface of CDs is passivated (during or after synthesis) by external agents [12], forming a layer of functional groups or molecules which bind to the carbonaceous core. The passivation layer should be considered as an integral part of the structure and function of CDs, which, in particular cases, can be as thick as a few nanometers [13]. Thereby, depending on the specific surface structures, CDs can be 
hydrophilic or hydrophobic [14,15]. As for the optical properties, different synthesis procedures yield subtypes of CDs capable of emitting fluorescence at different wavelengths. In fact, CDs can emit blue [16], green [1], or red light [17], and their fluorescence can be either independent of the excitation wavelength [18,19], or more commonly "tunable", in the sense that the emission peak continuously shifts as a function of the excitation wavelength [20]. Their fluorescence intensity can be sensitive to one particular ion in solution [21,22], or it can respond to a variety of interactions with other systems, such as carbon nanotubes (CNTs) [7].

Overall, CDs exist in different sub-types with different core and surface structure, stoichiometry (C content ranges from $50 \%$ to $80 \%$ ), and different specific optical characteristics. The main two characteristics which are truly recurrent in every type of $C D$ are the small size $(\approx 10 \mathrm{~nm}$ or less) and the surface functionalization layer, which is typically very dense and disordered [23]. Both of these features seem to be crucial to obtain CDs capable of visible photoluminescence with high emission efficiency. In particular, many studies have provided strong evidence that the passivating layer is mandatory for CDs to display a high luminescence, although the surface groups are not fluorescent by themselves.

Independently of the structural complexity, photoluminescence is certainly the most intriguing and, at the same time, the most unclear characteristic of these nanosystems. CD fluorescence is usually very strong [18,24-27], tunable [1,6,26,28-30], and sensitive to local environment: solvents [31,32], ions [22,33,34], pH [35], external agents such as carbon nanotubes (CNTs) [7,36]. Moreover, it usually occurs only when the nanoparticles are well dispersed. In fact, aggregation seems to turn off the emission $[37,38]$. Usually, electronic absorption of CDs covers both UV- and visible range. This allows to photo-excite CDs in a very broad spectral range, upon which one typically observes the tunability of the emission: the position of the emission peak changes with the excitation wavelength (Figure 1). This provides a multi-color emission spanning all the visible, although the absorption and the emission efficiencies usually decrease at longer wavelengths [39]. This emission is often characterized by a high quantum yield, which, however, strongly depends on the synthesis conditions. Many works demonstrate that this emission is very sensitive to the external environment and strongly responds to its changes [7,32,40-42]. For instance, CDs show a clear dependence of the emission band (peak and/or shape) on the solvent polarity (solvatochromic behaviour) [32,43]. In addition, CDs strongly respond to metal ions in solution. In fact, their fluorescence can be either quenched or enhanced in presence of metal cations $\left(\mathrm{Hg}^{2+}, \mathrm{Cu}^{2+}, \mathrm{Fe}^{3+}, \mathrm{Ag}^{+}, \ldots\right)$, the specific response being strongly dependent on the particular structure of $\mathrm{CD}$. Some CDs are also sensitive to other agents in solution as CNTs [7] or various molecules [40-42].

Carbon dots research is still in a developing phase despite thousands of studies have already been published on the subject, and several scientific open questions exist about their optical behaviour, the fundamental nature of the electronic states, the key factors determining their bright fluorescence, and the relation between structure and emission. Therefore, a large effort is in progress to find the most effective ways to tailor CDs for specific applications. While several review papers have been already published on CDs [4,44-51] focusing on different aspects of the field, this work specifically focuses on the most fundamental aspects of the photophysics and photochemistry of CDs, currently the subject of a large debate. After a brief presentation (Section 2) of the main synthesis methods, structural properties, and applications of CDs, the core of this paper is contained in Section 3, which aims to summarize the current understanding of $C D$ photophysics, from their fundamental emission features to their interactions with coupled systems.

\section{State of the Art}

\subsection{Synthesis of $C D s$}

Many different routes to produce CDs have been described in the literature. They can be classically categorized in two families: top-down and bottom-up approaches (Figure 2). 


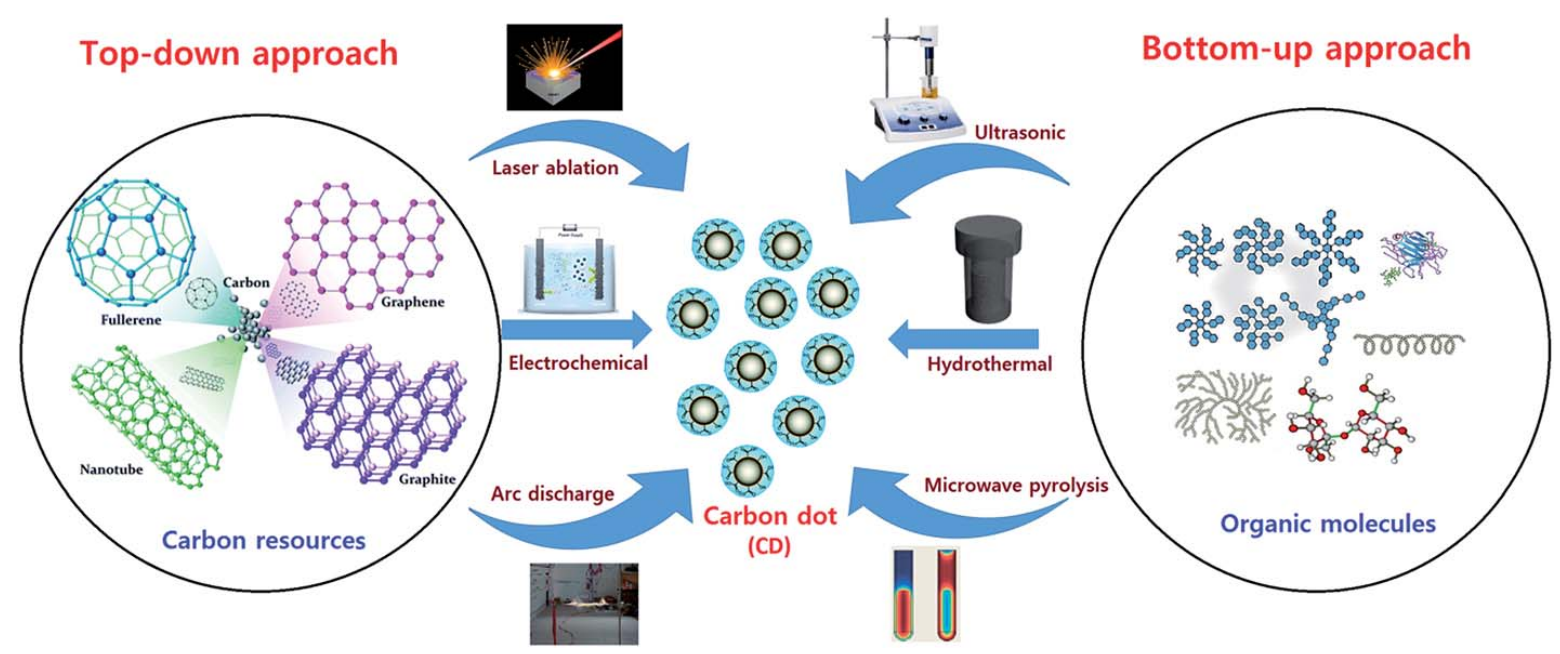

Figure 2. Representation of the possible synthesis methods to prepare carbon dots. Reproduced with permission from [52]. Copyright Royal Society of Chemistry, 2017.

Top-down methods involve the disruption of bulk carbon precursors or nanomaterials with higher dimensionality than CDs (considered zero-dimensional), such as graphite (bulk) or carbon nanotubes (1D material). Several methods can be used to transform these precursors into CDs (Figure 2), such as laser ablation [1], electrochemical synthesis [34], arc discharge [2], or chemical oxidation [23,28]. In general, the products from these types of synthesis are not immediately fluorescent. However, they can be typically transformed into highly fluorescent $C D$ s by passivating their surface with various polar moieties after synthesis, as reported by many groups $[1,28]$. Bottom-up syntheses usually exploit the carbonization (more or less complete) of different molecular precursors, as citric acid [53] or sucrose [54]. The carbonization of these compounds, typically chosen for their low melting points, can be carried out at relatively low temperatures to produce CDs the characteristics of which strongly depend on the reaction conditions. Besides "pure" carbon-core CDs, mixing the carbon sources with other molecular precursors, as urea [8] and thiourea [55] can be used as a method to dope the structure of CDs with nitrogen, sulphur, or other heteroatoms.

One important benefit of top-down synthesis routes is that the obtained CDs typically have simple and well-defined structures (e.g., graphitic nanosphere) that leave no room for structural ambiguity [56]. In contrast, bottom-up methods can be much harder to control: various side products (e.g., small fluorescent molecules) can be formed along with CDs, hence the need for a careful purification after synthesis. However, bottom-up synthesis methods bear their own advantages. On one hand, they are particularly simple and surface passivation can be usually achieved in "one pot" without the need of post-synthesis chemical processing. In fact, the surface of as-synthesized CDs via the most popular bottom-up procedures, spontaneously achieves the appropriate structure needed for an intense fluorescence. In addition, while the structure of CDs obtained by top-down synthesis typically resembles the structure of the precursors (e.g., graphitic CDs from laser ablation or chemical oxidation of graphite $[1,23,34,56])$, bottom-up routes are more versatile and yield a much larger variety of CD structures (see Section 2.2), especially with combined with doping strategies. The following paragraphs provide several representative examples of some widespread CD preparation methods.

\subsubsection{Laser Ablation}

Laser ablation was the first method used to produce CDs in a controlled way [1]. It is a top-down method which is frequently used for the production of many different types of nanoparticles, through the interaction of a pulsed laser beam with the surface of a target (solid precursor) and the consequent ejection of materials in the form of nanoparticles [57]. It has long been known that the 
ablation of a graphite target under certain conditions produces an aggregate of carbon nanoparticles $[1,58]$. Only after an acidic treatment of the surface and the following surface passivation by organic molecules, these carbon nanoparticles become bright luminescent and, therefore, can be described as "carbon dots" [1]. Later, many other works have been conducted on the synthesis of CDs via laser ablation routes, aiming to improve the control on the characteristics of the synthesized materials.

As is well-known for other nanomaterials [57], changing laser ablation parameters provides a way to control the CD characteristics. For example, Hu et al. [59] carried out a one-step synthesis of CDs from graphite flakes in polymer solution, and found that changing pulse duration from $0.3 \mathrm{~ms}$ to $1.5 \mathrm{~ms}$ of a $1064 \mathrm{~nm}$ laser beam allows to tailor CDs size from $3 \mathrm{~nm}$ to $13 \mathrm{~nm}$. These CD sub-sets present different morphology and various core structures: while the smallest particles are single mono-crystals, larger CDs are composed by multiple crystalline grains, and show a quantum yield which decreases with increasing size. A passivation procedure is not needed after this synthesis procedure, suggesting that surface passivation probably occurs simultaneously to the formation of nanoparticles, caused by the interaction of the ablation plume with the polymeric solution. Varying pulse duration seems to change the conditions of the nucleation and growth process and, therefore, changes the size distribution. Other works demonstrated that also laser wavelength is a key parameter during the ablation of a target. In Ref. [60], the authors demonstrate that ablating graphite with a wavelength in the UV-range $(355 \mathrm{~nm})$ produces $5 \mathrm{~nm}$-sized crystalline CDs without the formation of any aggregates, whereas the use of a beam at $532 \mathrm{~nm}$ or $1064 \mathrm{~nm}$ produces plenty of carbon aggregates. In addition, in this case, no post-synthesis functionalization is needed to obtain highly fluorescent CDs. In fact, the laser ablation is performed in acetone solution, wherein the laser interaction with the solvent probably induces the formation of radicals through the dissociation of solvent molecules, and their subsequent attachment to the surface of the nanoparticles, inducing their functionalization with ketone groups. Moreover, the authors studied the influence of the irradiation time and found a peak of emission efficiency after $150 \mathrm{~s}$ of ablation which decreases with longer times.

\subsubsection{Electrochemical Synthesis}

Electrochemical synthesis is a top-down method which exploits a redox reaction occurring in an electrochemical cell under the influence of an electric current applied between two electrodes (solids) separated by the electrolyte (liquid) [61]. The first electrochemical synthesis of CDs was described by Zhu et al. [16]. They demonstrated this novel method for the production of graphitic CDs with highly blue luminescence, where multi-walled carbon nanotubes (MWCNTs) were used as an electrode during the synthesis. The use of precursors with a graphitic structure turns out to produce prevalently graphitic CDs or GQDs, as confirmed by many later works $[11,62,63]$. An important step forward in the literature was the discover of the importance of an alkaline environment [62]. In fact, Li et al. demonstrated that using graphite rods as both the electrodes in an alkaline environment $(\mathrm{NaOH} / \mathrm{EtOH})$ allowed to produce graphitic CDs with bright emission, while the same experiment in acidic condition did not produce any fluorescent CDs. They suspected that the presence of $\mathrm{OH}^{-}$groups is the key factor for the formation and the oxidation of CDs surface which makes them luminescent, although the precise mechanism was not clarified. In addition, Shinde et al. [11] demonstrated the importance of the electrolyte showing that in an aqueous medium they were able to produce graphene nanoribbons from MWCNTs, while in non-aqueous media they obtained luminescent GQDs. Moreover, they were able to control the size of the product from $3 \mathrm{~nm}$ to $8 \mathrm{~nm}$, tuning the time of the electrochemical synthesis from $15 \mathrm{~h}$ to $7 \mathrm{~h}$. Another way to tune and control the diameter of CDs is to vary the applied potential [63]. In this respect, it seems that the higher the applied voltage, the smaller are the synthesized dots.

\subsubsection{Thermal and Microwave Decomposition}

Thermal and microwave decompositions are probably the most popular and widespread production methods of CDs in the literature. They are two similar bottom-up CD synthesis routes which exploit the partial carbonization of molecular precursors driven by thermal reactions, generally carried 
out in liquid phase (hydrothermal or solvothermal synthesis) upon heating in an autoclave or by exposure to microwaves. The first thermal decomposition used for the production of CDs was reported by Bourlinos et al. [14]. They prepared two different amorphous CDs from two different precursors. One sample was hydrophilic and was obtained from the carbonization of 2-(2-aminoethoxy)-ethanol salt. The other was organophilic, as obtained from the carbonization of octadecyl ammonium citrate salt. Both the samples showed the typical emission characteristics of CDs, such as the fluorescence tunability. The first microwave pyrolysis was reported in 2009 by Zhu et al. [12], who succesfully produced luminescent $\mathrm{CDs}$ by the carbonization of aqueous solution with different amounts of poly-(ethylene glycol) (PEG-200) and different saccharides (glucose, fructose etc). These dots are amorphous and display the typical fluorescence tunability, and the authors noticed that CDs are not luminescent if during the synthesis PEG-200 is not present. This result probably indicates that the role of PEG-200 is to passivate, during the synthesis, the surface of nanoparticles.

Since these two works, several more studies used these techniques to synthesize CDs because of many advantages with respect to top-down methods. In fact, these syntheses can be extremely low cost (some authors obtained CDs from raw materials as orange juice [64] or grass [20]), fast (few minutes), and generally do not need any further passivation, differently from most top-down routes. Furthermore, these syntheses allow for easily introducing external atoms which dope the system changing its structural and optical characteristics. In fact, bottom-up methods have allowed for obtaining the CDs with the highest emission efficiencies reported in the literature so far. The most common doping agent by far is nitrogen $[6,8,9,21,53,65-69]$, sulphur [22,70-72], but also boron [73-76] and phosphorous [77,78] have been used. It seems, in fact, that the introduction of these doping agents substantially modifies the structure and increases the fluorescence quantum efficiency of the nanosystem, although the physical mechanisms behind this is still unclear, and recently very debated $[8,9,68,79]$.

In particular, addition of nitrogen atoms seems to dramatically enhance the emission quantum yield. Indeed, $\mathrm{N}$-doping even in low content has been supposed responsible of a new electron trapping surface state facilitating a high yield of radiative recombination [80,81]. However, the influence of nitrogen atoms on the emission remains poorly understood, since there are several possible sites of nitrogen in $\mathrm{N}$-doped CDs, with variable influence on the electronic properties [82]. In addition, superficial organic moieties such as amide and amine $[80,81]$ in some studies have demonstrated that nitrogen influences the electronic properties by taking part to the core structure in various ways $[68,79]$. Indeed, high levels of $\mathrm{N}$-doping sometimes result in the formation of particular networks such as carbon nitride nanocrystals $[8,83]$, which are difficult or impossible to obtain by top-down methods, and display especially interesting characteristics.

\subsubsection{Purification and Separation Methods}

One widespread problem in CDs nanoscience is the heterogeneity of most CD samples, in the sense that several synthesis routes tend to yield CDs with a large degree of structural heterogeneity, such as very broad size distributions, large dot-to-dot variations in surface structure, optical heterogeneity, or the contamination of the sample by small fluorescent molecules produced together with CDs. Therefore, aside a few exceptions [84], the use of a purification method is often crucial to achieve a full control on the size dispersion of the synthesized nanosystems, or select some sub-sets of CDs based on their size or their surface structure. In some cases, separation methods have been used simply to select the most fluorescent part of a CD sample, out of a heterogeneous distribution of fluorescent quantum yields [10,85], leading to some of the highest fluorescence quantum yields reported in the literature. Besides the practical requirement of obtaining a tighly-controlled CD sample, obtaining CDs with simple and well-defined optical features is also helpful in order to relate the emission mechanism to a specific structure. 
The most common purification methods are dialysis [86,87] used to purificate a sample from small impurities, centrifugation [88], mostly used to remove any aggregates, size exclusion chromatography [10,89-91], and high performance liquid chromatography (HPLC) [25,92]. Size exclusion chromatography (SEC) has been used in many works to separate CDs by their size. In Ref. [89], the authors take advantage of this to obtain two fractions with different morphological and optical properties. In particular, they succeed in having two distinct CD samples which emit respectively in the green (the smaller) or in the blue (the bigger). In Ref. [10], SEC was used to produce a monodisperse sample with relatively narrow size distribution, a well-defined crystalline structure and exceptionally homogeneous optical properties. Arcudi et al. [90] used SEC in order to obtain a quasi-monodispersed samples, and, in Ref. [92], the authors used HPLC to obtain different fractions with different optical features which can be related to the size of the samples.

\subsection{The Structure of $C D s$}

Core and surface structures of CDs are quite synthesis-dependent, opening a great range of possibilities to design different types of CDs. In practice, CDs should be regarded as a relatively wide family of nanosystems, existing in several possible structural sub-types. While the core structure can be crystalline or amorphous, the surface shell which envelops the core can host different polar or apolar groups, ranging from small functional groups to long atomic chains. In the attempt to rationalize this variability, some authors tried to classify existing CDs in various sub-types [3]. Although no universal classification is currently accepted in the literature, we propose in (Figure 3) a classification of the most relevant types of CDs, based on their different core structures and morphologies.
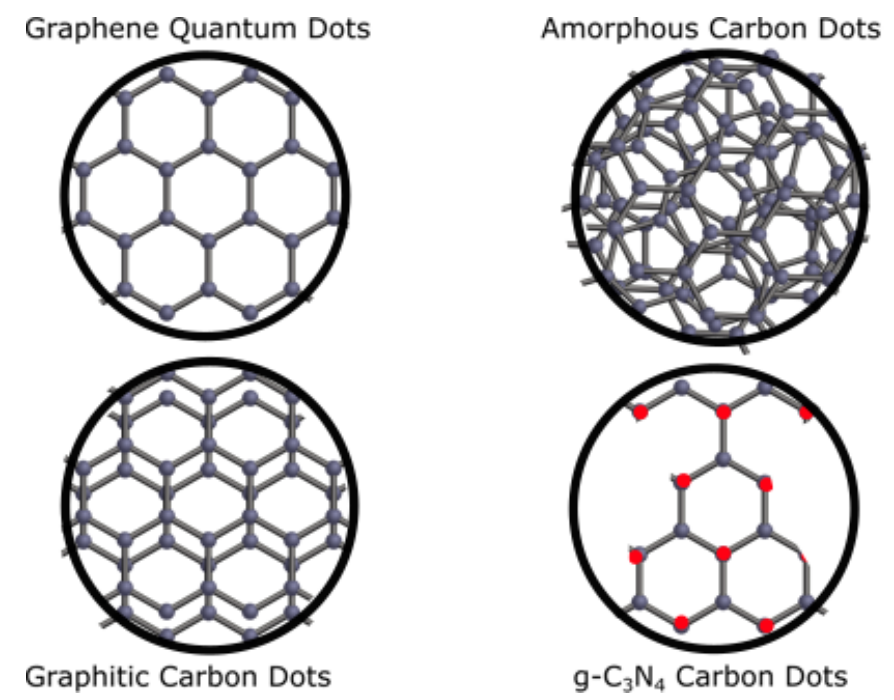

Figure 3. Schematic representation of commonly reported CD structures. Black and red dots represent Carbon and Nitrogen atoms, respectively.

Spherical-shaped graphitic CDs are probably the most common in the literature $[1,23,36,53,59,90,91,93-95]$, although it is worth noting that clear proof of a graphitic mono-crystalline structure of CDs via a thorough high-resolution transmission electron microscopy (HRTEM) study was achieved only by a few works $[5,68,95]$. As in graphite, the core of these dots is composed by layers of $\mathrm{sp}^{2}$-hybridized carbon stacked on top of each other, where the lateral dimension of the layers is limited by the overall dot diameter, typically of a few nanometers. The crystalline nature of the core is usually confirmed by the use of different structural techniques, such as high resolution transmission microscopy, X-ray diffraction (XRD), and Raman spectroscopy, as reported in Figure 4 where the graphitic core is visualized by HRTEM measurements. 


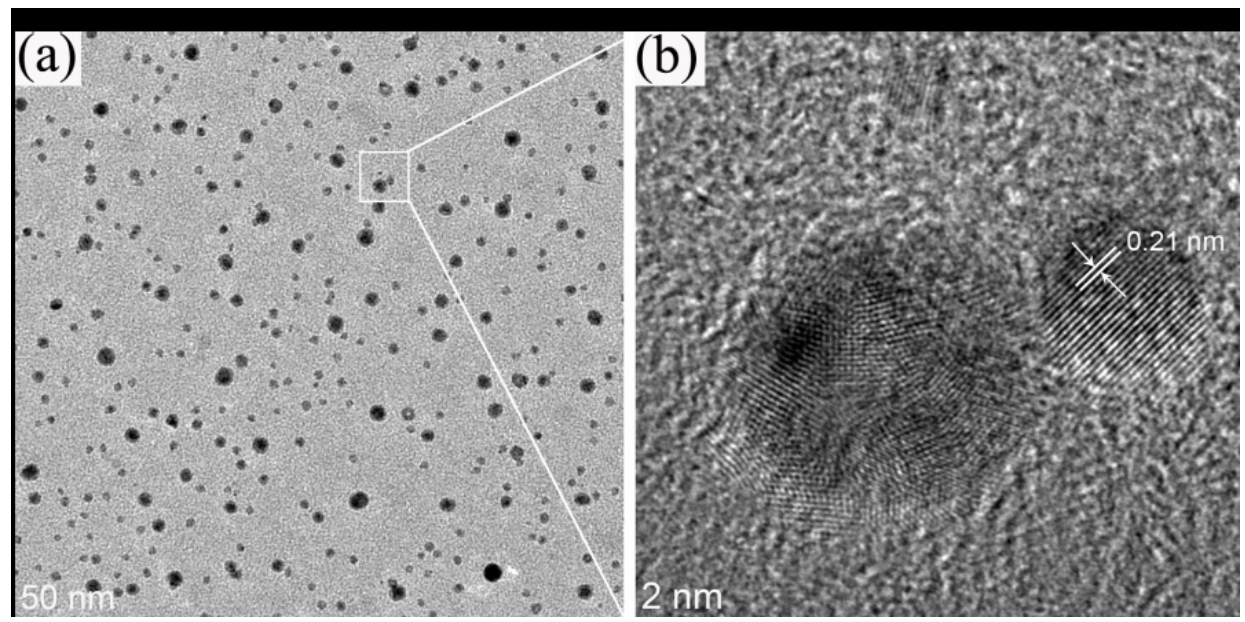

Figure 4. Transmission electron microscopy (a) and high-resolution transmission electron microscopy image (b) of CDs with graphitic core structure; the average lattice spacing of these CDs is $0.21 \mathrm{~nm}$ which is compatible with the (100) planes of graphite. Reproduced from [96] under the Creative Commons Attribution Licence (CC BY 4.0).

HRTEM usually needs to be combined with atomic force microscopy (AFM) to have full information not only on the crystalline core structure but also on the three-dimensional morphology, allowing in particular to discriminate graphitic CDs from GQDs [11,92,97]. The latter are not spherical particles but are small disks made by 1-3 layers of graphene stacked on each other. However, their optical characteristics are typically very similar to spherical CDs, and their fundamental understanding is equally unsatisfactory. In fact, the extent to which GQDs should be considered as a truly different system from CDs is still debated.

Going back to CDs, those with crystalline cores are not limited to a graphitic structure. In fact, other possible structures were reported for CDs synthesized in special conditions, particularly at high levels of $\mathrm{N}$ doping, where several groups reported $\mathrm{CDs}$ with carbon nitride structures, either in a graphitic- or $\beta$ - crystalline arrangement $\left(\mathrm{g}-\mathrm{C}_{3} \mathrm{~N}_{4}\right.$ or $\left.\beta-\mathrm{C}_{3} \mathrm{~N}_{4}\right)[8,10,33,83]$. Recent studies have demonstrated that the carbon nitride core structure appears when the amount of nitrogen dopants overcomes a defined threshold, above which the core structure is forced to diverge from its graphitic nature [68]. Notably, the two variants of carbon nitride CDs described in the literature are very different from each other: $g-C_{3} N_{4}$ is a layered material similar to graphite, in which each layer consists in the repetition of a structural motif consisting in three hexagonal rings where carbon and nitrogen atoms in $\mathrm{sp}^{2}$ hybridization are alternated (Figure 3). In contrast, $\beta-C_{3} \mathrm{~N}_{4}$ is an hexagonal network of tetrahedral bonded $\left(\mathrm{sp}^{3}\right) \mathrm{C}$ atoms connected to trigonal $\mathrm{sp}^{2}$ nitrogen atoms. Despite being a sp ${ }^{3}-\mathrm{C}$ material, the emission properties of $\beta-\mathrm{C}_{3} \mathrm{~N}_{4}$ dots are consistent with all the other types of CDs, showing the typically broad and tunable emission. In particular, $\beta-C_{3} N_{4}$ dots are very different from nanodiamonds [98], which have almost pure $\mathrm{sp}^{3}-\mathrm{C}$ cores, very large $(>5 \mathrm{eV})$ electronic bandgaps, and emit a characteristically narrow luminescence due to various point defects.

In addition, for the crystalline varieties, it is also possible to find many examples of amorphous CDs $[7,14,20,64,99-101]$, which contain a mixture of $\mathrm{sp}^{2}$ and $\mathrm{sp}^{3}$ hybridized carbon, in variable proportions, and without any long periodicity in the core. Except for the core structure, however, they apparently exhibit rather similar characteristics with respect to crystalline dots, such as high fluorescence. Among the amorphous varieties, another possible core structure has been recently proposed for some CDs synthesized by bottom-up procedures. This core structure involves the aggregation of small molecules which are formed usually during the carbonization of citric acid (a very popular precursos for CDs) $[102,103]$, and kept together in a quasi-spherical shape by comparatively weak interactions, like $\pi-\pi$, H-bonds, Van der Waals. 
Until now, only a core classification was presented. In addition, the surface of the dots can be very variable and hosts a variety of functional groups, mostly identified by infrared absorption (IR), X-ray photoelectron spectroscopy (XPS) and thermal gravimetric analysis (TGA). Generally speaking, the surface functional groups establish if the sample is hydrophilic or hydrophobic [14,104]. Hydrophylic CDs are much more common, and usually display very polyfunctional and disordered surface structures, characterized by an abundance of small polar groups, such as Hydroxyl, Carboxyl, Carboxylate, Amine, and Amide. Besides "standard" polar groups, some authors passivated the surface with more complex molecules, as polyethylene glycol (PEG), or polyethyleneimine (a long chain molecule which contains primary, secondary and tertiary amine groups), still obtaining highly fluorescent CDs $[29,35,99,105]$. The high water solubility (typically several $\mathrm{g} / \mathrm{L}$ ) of most CDs is a characteristic, which is very useful for many applications.

As already mentioned, it is widely accepted that the presence of a proper surface passivation is mandatory to have bright fluorescence from CDs. In fact, deliberate chemical passivation of the surface is often necessary after the synthesis (especially through top-down routes) in order to obtain highly fluorescent CDs $[1,36,93,94,106]$. Based on the major influence of the surface passivation on the fluorescence, and considering that both amorphous and crystalline dots display a similar optical phenomenology, it may seem that the core has a negligible influence on the emission mechanism and that only the surface plays a key role in the emission. Despite of this, some authors $[107,108]$ provided evidence that the core can be as fundamental in the photocycle of CDs as the surface. These issues will be discussed in more detail in Section 3.

\subsection{Applications}

Because of their unique blend of properties, CDs are very promising for many applications. They offer the perspective of a C-based equivalent of optically-active quantum dots (QDs) with the additional benefits of C-based materials, as the absence of toxic elements (typically heavy metal atoms) which limit, in particular, the use of QDs in bio-oriented applications. The bright emission of CDs, combined with the marked electron-donor capability can be exploited for instance in optoelectronic devices $[45,105,109-111]$. The sensitivity of the emission to metal ions in solution can be exploited to create nanosensors capable of recognizing different cations [26,112-117]. Their non-toxicity is a key advantage to perform in vivo [118-122] and in vitro [41,67,113,123-125] bioimaging experiments and drug delivery experiments [126]. Indeed, the range of applications of CDs is surprisingly wide: for example, antiviral [127,128] and antibacterial [129] properties of CDs were recently discovered, and CDs were even used as nanoweapons against mosquitos [130], or as a component of fluorescent inks $[53,89]$. So far, the majority of CDs-based devices have been developed and tested just in a laboratory environment. However, their commercial and industrial exploitation should not be too far away. The next paragraphs illustrate the technological versatility of CDs through a selection of different possible applications.

\subsubsection{Nanosensing Applications}

In the literature, nanosensors based on CDs were developed by two different strategies: (i) the nanosensors simply consisted of "pure" CDs, as-synthesized or passivated through specific target groups; and (ii) the functional sensing material was a nano-composite fabricating by coupling CDs with other nano- or micro-materials.

The use of CDs as "raw" sensors is quite common in the literature [131]. Differently prepared CDs can be applied to detect various metal cations as $\mathrm{Hg}^{2+}, \mathrm{Cu}^{2+}, \mathrm{Fe}^{3+}[23,26,112-115,132]$, or small molecules or macromolecules in solution, even in a biological context [122,133-137]. Typically, when CDs are dissolved in a solution with a specific analyte, their luminescence is quenched (decreases), allowing to detect the analyte with high sensitivity and, often, high selectivity, as obtained by a proper engineering of the surface functional groups, interacting only with a given type of metal cation. The detection sensitivity can be very high and the minimum concentration of detectable ions can be 
as low as femtomolar [138]. However, the fundamental causes of quenching are very debated and may involve different fundamental interactions, such as a charge transfer from the dot to the ions, which hinders radiative recombination [139], or an energy transfer from the dots to the acceptor, quenching the emission of CDs and enhancing the emission of the latter $[140,141]$. Because of such a poor understanding, the engineering of these applications still proceeds mostly through trial-and-error routes. Only in recent times, the use of the appropriate advanced methods, such as femtosecond spectroscopy is beginning to shed light on the fundamental mechanisms behind these interactions of CDs, as will be discussed in more detail in Section 3.4.

As compared to metal cations or small neutral molecules, it is less common to find in the literature examples where CDs are used to detect anions [142] probably because CDs surfaces are usually negatively charged $[143,144]$. The few existent articles describe the indirect detection of negative ions as $\mathrm{PO}_{4}^{3-}$, or $\mathrm{S}^{2-}$, or $\mathrm{SCN}^{-}$through the combination of $\mathrm{CDs}$ and a cation $[116,117,145]$. CD emission, quenched by the cation, is recovered by the presence of anions which inhibits the quenching effect of the cations. This strategy is sometimes used in the second type of nanosensors. In some works, the authors proposed CD-based nanosensors where CDs are coupled to molecules $[140,146]$ like rhodamine, or to nanomaterials such as gold nanoparticles [145], or metal organic frameworks [141,147-149]. The sensing occurs both by emission quenching or emission enhancing as a result of the detachment, for instance, of the nanoparticle from the surface of the dot induced by the presence of the analyte.

CDs are also used in, so-called, ratiometric sensors. Taking advantage of the simultaneous presence of two emission bands peaked at different wavelengths (referred to as dual emission), displayed by some CDs, one can use the variation of their intensity ratio as the physical observable to infer the amount and the type of the analyte $[150,151]$. Indeed, in the same sample, different interactions with the analyte can affect the chromophores responsible of the two bands. Therefore, the analyte can quench them at different rates, causing a change of their intensity ratio.

\subsubsection{Biological and Nanomedical Applications}

To be safely applied in bioimaging, biosensing and nanomedicine, biological effects of a nanomaterial should be extensively investigated. Traditional QDs, such as $\mathrm{CdTe}$, have been used in various optical bioimaging experiments. Considering that QDs often contain toxic heavy metals, their application has to be well-controlled because of toxicity and environmental problems. Due to the bright photoluminescence and low toxicity, $\mathrm{CDs}$ are an attractive candidate for bioimaging applications. Indeed, cytotoxicity studies in vivo (on zebrafish [121]) and in vitro $[119,120]$ generally show that CDs are not toxic. For instance, Kang et al. [121] demonstrated that the introduction of CDs into zebrafish embryos and larvae does not influence their development. Furthermore, they established the possible use of CDs as fluorescent bioimaging agents in living systems.

Other studies revealed further benefits of CDs for these applications. For instance, Shereema et al. [123] demonstrated their antiangiogenic effect on vessels by finding a significant reduction in the proliferation of tumoral membranes after a treatment with CDs. This gave the basis for using CDs in the field of cancer therapy. Besides medical applications as anticancer or cancer targeting [120], CDs can be used as photo-activated [127] or not [128] antiviral agents, and photo-activated antibacterical [129] agents. For instance, they were used to reduce the entry of hepatitis $C$ viruses into monkey kidney cancer cells and human lung cancer cells physically blocking the passage of the virus [128].

Furthermore, the versatility and ease of functionalization of CDs, combined with their bright fluorescence, allows for using them as highly multifunctional nanotools in a biological context. A good example of this combined advantages is reported in Ref. [125] where CDs are decorated with a mitochondria targeting ligand and functionalized with a photoresponsive NO-releasing ligand. This system recognizes cancerous cells, wherein it attaches to the mitochondria and, then, upon irradiation, it is able to release for a long time nitric oxide, which is known to be a good therapeutic agent. 


\subsubsection{Optoelectronic Devices}

CDs are also promising for use in optoelectronics devices, thanks to their strong absorption, intense and tunable emission, but also to their electron donating and/or accepting character. Many authors employed CDs in the construction of light emitting diodes (LED), wherein CDs can be used in two different ways: as fluorescent downconverters [111], or as the active layer in an electroluminescent device [105]. The former is founded on the capacity of CDs to be photoexcited by UV and blue light and the following visible emission and exploits the tunability of the emission and the high quantum yield in order to obtain white LED. The latter design takes advantage of the electroluminescence from a CD layer, using CDs as an emitting layer in a multilayered structure after the external injection of charges. Besides LEDs, lasers represent another possible light-emitting device that can built from CDs. After the first pioneering demonstrations of CD-based lasers [152,153], the performance of such devices is recently growing, thanks to the advancements in CD synthesis methods $[10,18,154]$.

Last but not least, another important use of CDs is in solar cells [109,110,155]. In fact, it is well known that CDs display a long tail of strong visible absorption, very convenient to harvest solar light. Combining this with the high capability to accept or donate an electron from the photo-excited state, they become an excellent candidate to be used as sensitizer in solar cells, the photocathode of which can be built, for instance, by sensitizing $\mathrm{TiO}_{2}$ with $\mathrm{CDs}$ [110]. Furthermore, it seems that using a CDs film as an intermediate layer in a solar cell can be helpful to speed up the electron transport between other materials, for example from a perovskite layer to titanium dioxide [109].

\subsubsection{Photocatalysis}

A photocatalyst is a substance which, upon photo-excitation, becomes capable of speeding up a chemical process. CDs have been proposed several times as active materials in photocatalytic applications [156]. Their absorption and electron transfer properties, and the ease of coupling to other materials as $\mathrm{TiO}_{2}$ [157], $\mathrm{Fe}_{2} \mathrm{O}_{3}$ [158] or $\mathrm{SiO}_{2}$ [62] are particularly beneficial for these applications. In general, CDs are employed in two different ways, as pictured in Figure 5 [157]. On one hand, they are used as a photo-sensitizers: after absorption of light, CDs transfer a photo-generated electron to a coupled semiconductor which otherwise would only absorb in the UV (Figure 5b). In this way, the catalytic action of the composite is extended throughout the visible range. On the other hand, they can be used as acceptor of charge carriers from the photoexcited semiconductor, in order to slow down or suppress the recombination of electrons and holes (Figure 5a), thus increasing the possibility of chemical reactions and enhancing photocatalytic properties.

a

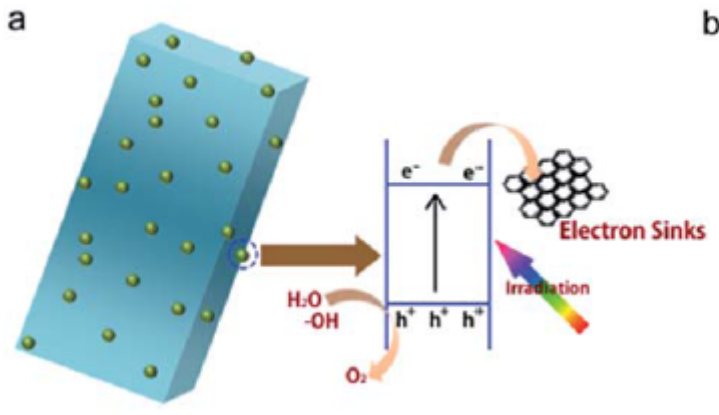

b

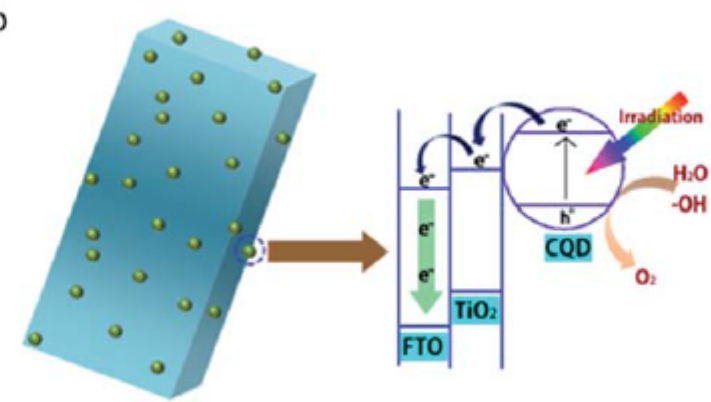

Figure 5. Possible uses of CDs (yellow spheres) in a photocatalytic application: (a) as electron acceptor (electron sink) from the semiconductor surface (blue block) increasing the photocatalytic activity of the semiconductor; (b) as electron donor creating a cascade of electrons from CDs lowest unoccupied molecular orbital (LUMO) to semiconductors. Reproduced with permission from [157]. Copyright Royal Society of Chemistry, 2014. 
Although most of the photocatalytic applications of CDs are based on CD-semiconductor composites, some works reported photocatalysis of "raw" or simply-functionalized CDs, such as water splitting or $\mathrm{CO}_{2}$ conversion [159]. Cao et al. functionalized CDs with a shell of gold or platinum and used them to harvest visible photons, followed by charge separation on the particle surface in order to drive the photocatalytic process for the reduction of $\mathrm{CO}_{2}$, or for the photo-production of $\mathrm{H}_{2}$ molecules from water splitting. Mehta et al. [160] succeeded in fabricating the "opposite" nano-devices, consisting in a gold nanoparticle functionalized with a surface nanometric layer structurally equivalent to a CD. The authors took advantage of the surface plasmon resonance of gold nanoparticles to enhance the photoexcitation of the composites, ultimately resulting in the production of hydrogen through the splitting of water molecules.

\section{The Photophysics of CDs}

The bright fluorescence displayed by CDs is uncommon in other carbon-based nanomaterials. CDs emission bands are always very broad: their full width at half maximum (FWHM) is $\approx 50-100 \mathrm{~nm}$, and usually combined with a structureless electronic absorption spectrum which slowly decreases at long wavelengths [39]. Sharper bands are sometimes superimposed to this broad absorption, and they are usually associated with surface groups, such as the $n \rightarrow \pi^{*}$ transitions associated with the non-bonding orbitals of carboxylic groups. The variability of CDs synthesis routes and structures complicates the clarification of the emission mechanism. In this respect, an important goal in the field would be disentangling the contribution of quantum effects, surface states, or molecular-like states to the emission mechanisms, and tracing them back to the core and surface structures of different CDs.

The small size of these nanosystems may suggest the emission mechanism to involve some form of quantum confinement effect. On the other hand, the role of passivation and the sensitivity to external agents point to a fundamental role of the surface states [1]. To complicate the matter, recent experimental evidence has strongly suggested that the emission of some CD sub-types is actually related to molecular fluorophores, either free or adsorbed on the surface of the dots $[88,161]$, rather than to the nanoparticles themselves.

This section is organized as follows: Section 3.1 reviews the various proposed models to explain $\mathrm{CD}$ emission and the open debate in the literature. In Section 3.2, we discuss the interpretations to explain fluorescence tunability, one of the most characteristic features of CD fluorescence. Section 3.3 deals with the interaction of CDs with various coupled systems, such as metal ions, which are particularly important for photocatalytic and sensing applications. Finally, Section 3.4 specifically covers the existing work conducted on CDs through femtosecond spectroscopies, a family of methods which have been allowing to make several steps forward in the understanding of $C D$ photophysics.

\subsection{Emission Mechanisms}

A common and well-understood phenomenon typical of semiconductor QDs [162], such as CdSe or PbSe, is the quantum confinement effect: if the crystal size is reduced below the exciton Bohr radius, the optical and electronic properties become size-dependent. The most peculiar manifestations are the increase of the band gap, the progressive transition from a continuous to a sparse density of states, and various important changes of the photoexcited relaxation dynamics [163,164].

As for carbon nanomaterials, one may begin with considering an ideal, infinite sheet of graphene, that is a perfect $\pi$-conjugated carbon monolayer without electronic bandgap, which cannot be emissive unless suitable modifications are carried out. Indeed, graphene can be made emissive by introducing luminescent structural defects, as commonly observed in functionalized CNTs and nanodiamonds [98,165]. However, another possible strategy is cutting graphene sheets into small pieces, in order to enter the quantum confinement regime [165] and increase the fundamental energy gap. In fact, many theoretical simulations carried out on GQDs show that the emission peak depends on the number of graphene-like rings or, in other words, on the size of $\mathrm{sp}^{2}$ domains [166-170], leading these authors to attribute GQD emission to a quantum confinement effect. This type of 
emission, involving band-to-band transitions, is often called intrinsic emission, many authors referring to the states involved in these transitions as intrinsic states.

Considering now the more general case of CDs, characterized by a quasi-spherical shape and graphitic structure, and taking into account their very small sizes, one can hypothesize that their emission originates from a similar, quantum confinement effect. Thereby, the emissive chromophore would be the nanometric-sized, conjugated $\mathrm{sp}^{2}$-domain constituting (or contained in) the $\mathrm{CD}$ core. Such an interpretation was endorsed by several works in the literature $[62,166,169,171]$, and qualitatively agrees with the fact that carbonaceous nanoparticles only become "carbon dots", i.e., highly fluorescence, after they are reduced to very small sizes. Indeed, in some works, the authors controlled the size of CDs during the synthesis $[166,171]$ or after it by fractionation procedures [62], and recorded an emission which displays a regular size-dependence. Typically, these works reported that the smallest CDs display the bluest emission, as expected in a quantum confinement regime. For instance, $\mathrm{Li}$ et al. [62] reported an optical study of four $\mathrm{CD}$ fractions sized from $1 \mathrm{~nm}$ to $4 \mathrm{~nm}$, and found an emission which blueshifts with the reduction of the size (Figure 6). However, several problems exist with this interpretation. If quantum confinement affects the whole graphitic core, it should only apply to ultra-small sized CDs because the bandgap of $\pi$-domains with a diameter of $2 \mathrm{~nm}$ is already too small $(1 \mathrm{eV})$ to emit visible light [172]. Furthermore, other works have demonstrated for CDs a red-shift of the electronic transition energy with decreasing size, which is exactly opposite to what would be expected from quantum confinement $[89,173]$.

a)

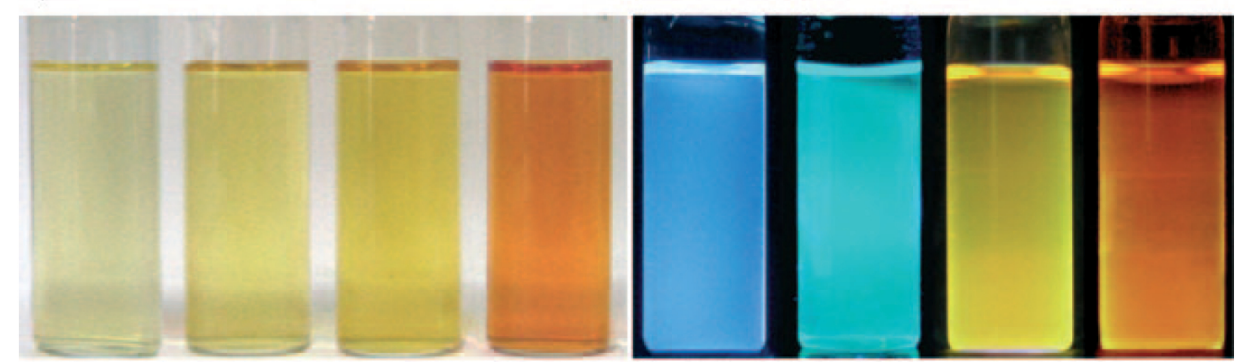

b)

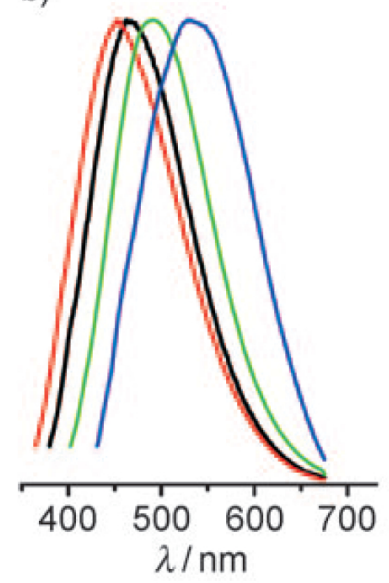

c)

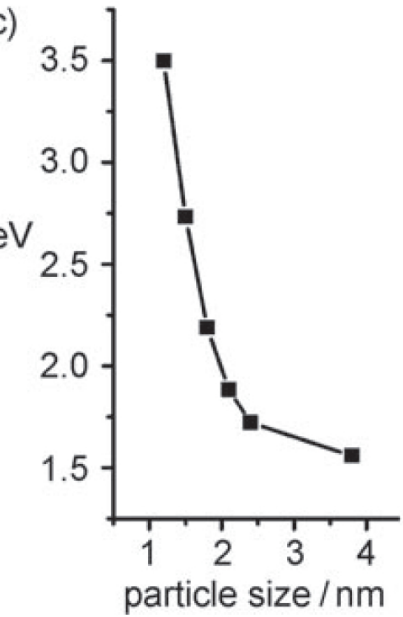

d)

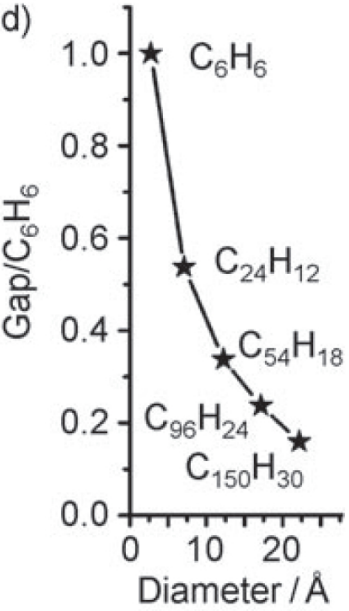

Figure 6. (a) solutions of CDs with different sizes under daylight (left) and UV light (right; $365 \mathrm{~nm}$ ); (b) emission spectra of different fractions: the red, black, green, and blue lines are the emission spectra for blue-, green-, yellow-, and red-emitting CDs appearing in panel (a), respectively. (c) CDs size vs. the emission peak; (d) Electronic gap dependence on the size of the graphite fragments, as obtained by quantum chemical calculations. Reproduced with permission from [62]. Copyright John Wiley and Sons, 2010. 
Therefore, it is widely believed that CD optical properties cannot be simply explained by the transitions between intrinsic states. In contrast, the emission of many CDs seems overwhelmingly influenced by extrinsic contributions mostly related to the surface: emission from surface defects, surface charge traps [1,174], or surface molecular-like states [166]. Indeed, there is a lot of experimental evidence that supports the idea of an emission which involves the surface. For instance, an appropriate passivation procedure is crucial to obtain highly fluorescent CDs [56], and CD fluorescence strongly depends on $\mathrm{pH}[31,175]$ and solvents [32,43]. More generally, the chemical characteristics of the surface, as, for example, the degree of oxidation, seem to have a dramatic influence on the emission quantum yield $[176,177]$. These surface treatments probably change the number of surface emissive traps, their emission efficiency and stability, and the alignment of the energy levels with respect to the energy gap, influencing the emission peak and the quantum yield.

The involvement of intrinsic and extrinsic states in the optical response of CDs are not mutually exclusive, and the interaction between the two is a difficult problem. In fact, it seems very likely that the nature of this interplay is highly structure- and synthesis-dependent.

On one hand, some authors simply proposed that the emissive surface states are completely independent of the crystalline structure of the core [14]. However, it has been impossible to precisely relate these chromophores to any specific functional group on CD surfaces. In fact, the situation could be more complex: a recent study systematically compared the optical properties of CDs with different surface functionalization, and provided evidence that the emissive states are highly delocalized on the disordered surface shell, thus involving simultaneously a large number of functional groups [23].

On the other hand, depending on the structure of the dots, various possible forms of interplay between core and surface states have been proposed. Wang et al. [178] tried to disentangle the role of the core and the surface investigating three samples with a different degree of crystallization of the core and similar emission characteristics. By ultrafast spectroscopy (see Section 3.4 for more details), they demonstrated that the excited-state behavior is the same in all the samples, but the quantum yield depends on the degree of crystallization. In particular, according to their model, the core is initially photoexcited and an exciton is created, which is later transferred to the surface and the charges are separated on surface traps. Finally, recombination of the trapped charges produces the emission. In another work on GQDs, Zhu et al. [166] compared the spectroscopic properties of four samples with different sizes, finding that the intrinsic state depends on the size but the optical properties are conditioned by the edge states because the emission depends on the alignment between the latter and the intrinsic state. When a system is photoexcited, the intrinsic states are populated, and if the edge states are intra-gap states, they are populated from the intrinsic states and therefore the emission originates from the radiative recombination from the edge states to the ground state; on the contrary, if the energy separation between the edge states and the ground states is higher than the band gap, they are not involved in the emission, which comes from band-to-band recombination (Figure 7).

Broadly speaking, a widespread model used to describe CD optical properties is that of a core-to-surface migration of the excitation. According to this idea, the core of CDs behaves as the optical antenna responsible of initial photon absorption. Then, spontaneous charge separation occurs and electron and holes are trapped on surface states. Finally, the fluorescence stems from a radiative recombination of these charges, released from the surface traps. This interpretation of CD optical transitions was born together with CDs [1], and later endorsed by many other authors [54,107,108,166,179], but finding convincing experimental evidence of these ideas has been difficult. 

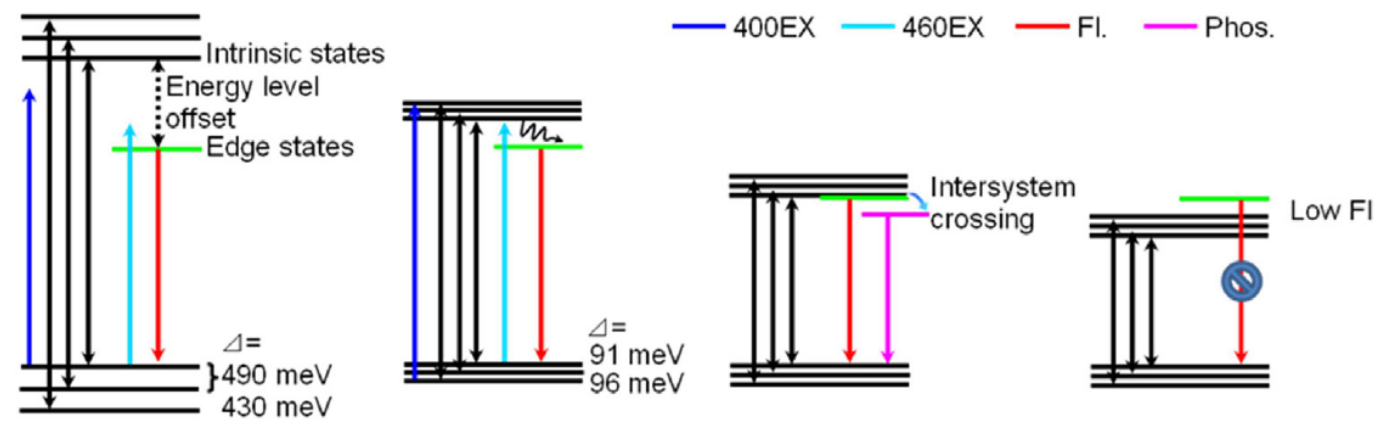

Figure 7. The electronic level structures of CDs of different sizes, as proposed in [166]. The intrinsic state depends on size, hence the energy level offset with the edge state, which ultimately decides the optical properties. Certain alignments between states also open a possibility for intersystem crossing and subsequent long-lived triplet emission. The latter, however, is very difficult to observe experimentally in most CDs. Reproduced with permission from [166]. Copyright Elsevier, 2014.

Another contrasting model recently proposed in the literature is based on the idea of an optical charge transfer transition, in which a surface-localized exciton is directly formed at the time of photon absorption [43]. In this model, supported by solvatochromic, time-resolved and single-molecule fluorescence studies, an electron transfer from core states to surface traps already occurs at the stage of photo-excitation, and the fluorescence is due to the inverse recombination transition. The spectroscopical fingerprints of the CDs that adhere to this mechanism seem to be a well-defined charge transfer band observed in the electronic absorption spectra, and a single-exponential fluorescence decay [43], both in striking contrast with the broad, unstructured optical absorption and multi-exponential decays observed for most CDs [39,180,181].

More recently, the emission of CDs produced by some specific (and very popular) bottom-up methods has been the subject of a particularly lively debate. Several authors proposed that the blue emission of these types of CDs is actually due to simple, small fluorescent organic molecules attached to CD surfaces or bound to the $\pi$-conjugated core, rather than to the dot itself $[182,183]$, while other works attributed the emission of some types of dual-emitting dots to aggregates of several molecular chromophores [19,184], and some even claimed a role of free molecules diffusing in solution [185]. Indeed, it has been established that some bottom-up syntheses of CDs can produce small fluorescent molecular derivatives, formed alongside with the carbonization process, both if the synthesis is carried out in water [183] or in an organic solvent [15]. In particular, the production of CDs from the decomposition of citric acid and a N-containing precursor lead to the formation of 2-pyridone derivatives [91,182], such as citrazinic acid [102,183,184], and the relative yield of the molecular byproducts and CD cores changes in favour of the latter at higher synthesis temperatures $[161,186,187]$.

There is a lot of evidence supporting these ideas, as the similarity of the blue emission of cytrazinic acid at $420-440 \mathrm{~nm}$ to the blue fluorescence of many CDs obtained from citric acid [88,188], theoretical simulations $[103,183]$, and the lack of tunability of the emission band of these CDs, in striking contrast with the behaviour of $\mathrm{CD}$ fluorescence excited at lower energies, which is strongly tunable [161].

Unfortunately, the emission due to the molecular chromophores and the one associated with the dot itself can be very hard to discriminate. Song et al. [161] produced a sample with a blue optical activity independent of excitation wavelength and another emission band which is tunable. They investigated these two activities and suggested that their origin is different: the tunable emission is associated with electronic transitions which involve the core, while the non-tunable one is related to the presence of small molecules in solution. In particular, these molecules are supposed to exist in two forms: free in solution or attached to dot surfaces. Schneider et al. [88] found that the blue emission of CDs peaking at $430 \mathrm{~nm}$ decays with a bi-exponential kinetics, leading to hypothesize the 
presence of two forms of the same chromophore: one attached to the dot, and the other free in solution. Wang et al. [183] investigated the effect of UV-photobleaching on CDs. They combined experimental studies on CDs and on citrazinic acid with theoretical simulations and proposed a model in which the chromophore is a molecule of citrazinic acid attached to the surface of the dot.

Last but not least, another recently proposed model for the origin of CDs emission pictures the dots as excitonic H-aggregates composed by molecular chromophores stacked on each other [189]. The result of this stacking is the splitting of the excited energy level of the single chromophore, leading to the large Stokes shift typical of CDs. However, this mechanism guarantees exciton delocalization over the entire particle which behaves as a single emissive dot, thus overcoming the idea of a "molecular" chromophore localized on the CD surface.

Notwithstanding the several studies on the emission mechanisms of CDs, no unique model exists yet to explain its origin. The debate is still open and, probably, it is complicated by the variability of CDs, which not only affects CDs obtained by different synthesis procedures, but is also testified, even more dramatically, by the heterogeneity exhibited by the majority of CD samples.

\subsection{Origin of Emission Tunability}

One of the most intriguing characteristics of CDs is the tunability of their emission: the fluorescence peak of a typical CD shifts continuously when changing the excitation wavelength (Figure 1). Its origin is very debated in the literature and still lacks a clear explanation. Many authors attribute this tunability to a certain degree of inhomogeneity which typically affects CD samples, caused by the difficulty of tightly controlling the structural characteristics of the product obtained through most synthesis routes. Accordingly, CDs which display an emission independent of the excitation wavelength are considered quite homogeneous $[10,18,190]$.

Indeed, such a tunable, multi-colour emission can be very useful in many applications as mentioned in Section 2.3, but notwithstanding its benefits, the inhomogeneity of the sample hides spectroscopic information which might be very useful to understand the photophysics of the system and to rationally tailor CDs to specific applications.

At the spectroscopic level, the large inhomogeneity of most CD samples is pointed out by many experimental pieces of evidence, such as: broad unstructured absorption or emission bands, non-exponential kinetic traces in fluorescence decay [180], and differences between ensemble and single-molecule experimental results [191]. Its structural origin has been related to several factors as a chemical variability of CDs surface structure or charge from dot to dot [106,192], broad distribution of the size or shape irregularity $[62,92,170]$, variability of the density of emitting states on different dots [89], or presence of different types of CD aggregates in solution [193].

Therefore, the problem is twofold. On one hand, synthesis procedures of CDs are still unable to produce CDs with sufficiently homogeneous structural characteristics, such as narrow, monodisperse size distributions. On the other hand, the origin of $\mathrm{CD}$ fluorescence still being debated a lot, more systematic and focused studies are needed to precisely pinpoint the structural parameters which need to be controlled in order to obtain CDs displaying spectroscopically homogeneous optical features. However, the existing attempts to address these problems have produced very contrasting results, as explained hereafter. Therefore, explaining and controlling CD fluorescence tunability remains one of the most debated problems in the literature.

Unfortunately, it is not easy to unravel the knot of heterogeneity with standard optical measurements at the ensemble level. Therefore, a few works have tried to approach the problem by using two alternative ways: a single-molecule investigation $[43,189,191,192,194]$, and fractionation experiments $[25,106]$.

Fractionation allows for isolating the characteristics (optical, structural and morphological) of a sub-type of CDs, selected out of a sample according to one physical property (size, surface charge, etc). This should allow for correlating specific structural parameters to the optical properties, and possibly allow to isolate sub-types of monodisperse CDs. Differently, single-molecule experiments can be seen 
as a random fractionation down to the level of single dots, or aggregates of a few dots. These experiments aim to answer to important questions, such as whether the tunability is still preserved at the single dot level or, in contrast, every dot acts as a single non-tunable emitter, or if the fluorescence decay kinetics observed in the overall $C D$ ensemble is the same with respect to the single nanoparticle.

The very few existing experiments on single CDs revealed much information related to emission and to tunability. Dispersing an extremely diluted solution on a substrate allows for collecting the emission from individual dots (or small aggregates composed by few dots). Usually, single dots display narrower emission spectra than the ensemble measurements (refs. [43,191] and Figure 8a) pointing out the inhomogeneous width of ensemble emission bands, which are probably due to the superposition of the emission of individual dots, the peaks of which strongly fluctuate from dot to dot. Furthermore, Ghosh et al. [191] demonstrate the disappearance of the tunability at single dot level, as in Figure $8 \mathrm{~b}$, which suggests that a single dot acts as a single quantum emitter, with its particular energy gap. Therefore, spectral heterogeneity would only appear at an ensemble level due to the superposition of the spectral characteristics of several CDs $[189,191]$.
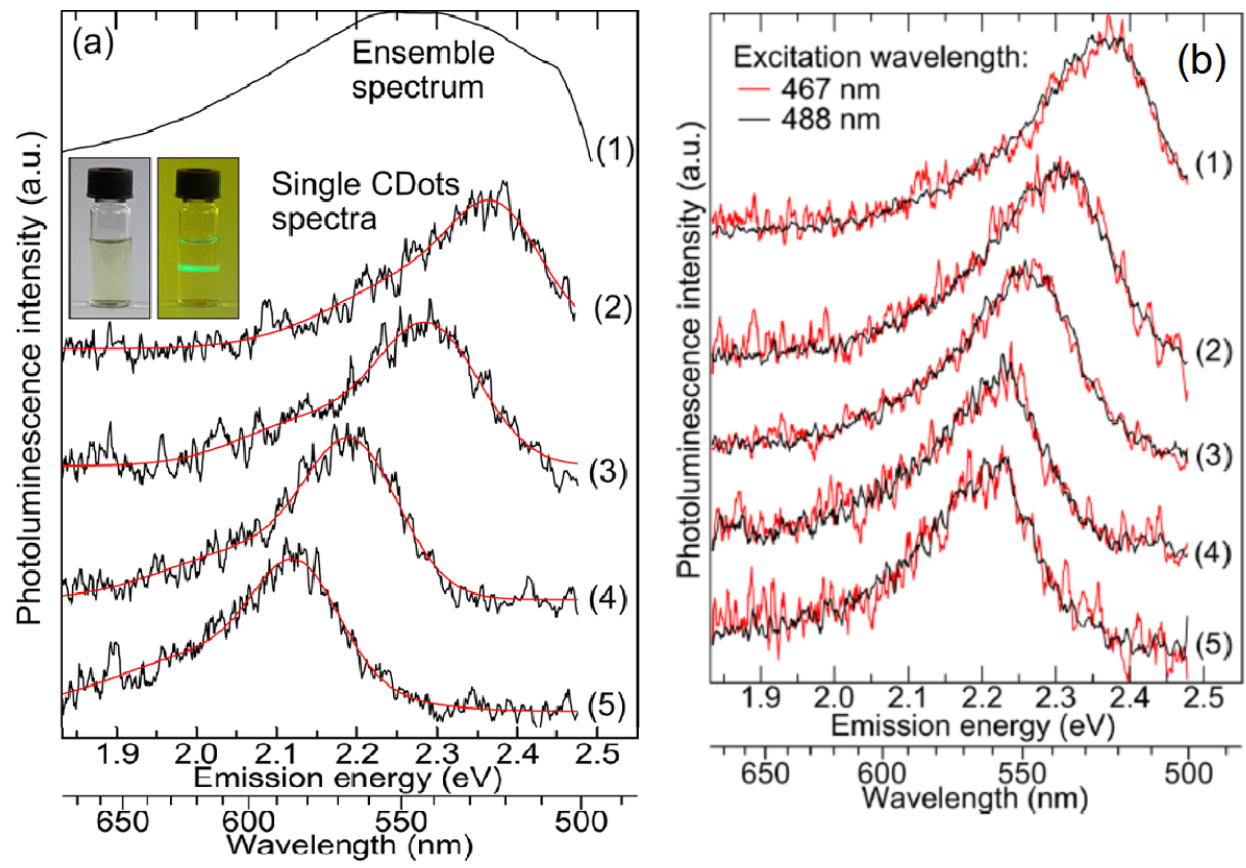

Figure 8. (a) (1): Ensemble emission spectrum excited at $488 \mathrm{~nm}$; (2)-(5): emission spectra from individual dots excited at $488 \mathrm{~nm}$; (b) (1)-(5) emission spectra from individual dots excited at $467 \mathrm{~nm}$ (red curves) and at $488 \mathrm{~nm}$ (black curves). Reproduced with permission from [191]. Copyright American Chemical Society, 2014.

In the same work, the multi-exponential decay of emission is also not observed in single dots, suggesting that also the multi-exponential decay is a fingerprint of heterogeneity, arising from dot-to-dot differences in excited-state lifetimes [191].

However, these results were disputed by other works. In fact, other papers reported that the tunability is observed even at the single dot level [6], showing that a single dot can emit different colours if excited at variable energy, indicating the presence of independent emission sites within a single CD, in striking contrast with the results of Ref. [191]. This evident contradiction between the results may be related to different experimental conditions. In particular, because of their very small sizes, it can be hard to discriminate between truly "single" dots and aggregates of a few dots. Therefore, it is possible that claims of tunability at the single-dot level are actually due to the emission from small 
aggregates of CDs as sometimes observed in other systems [195] and, therefore, the tunability is just related to the superposition of emission of different dots.

To address the origin of tunability, a second method consists in the selection of a part of the as-synthesized original sample according to various criteria which span from surface charge [106,196] to particle size $[10,25,62,89,92]$. Any of these separation methods is helpful to provide a more homogeneous sample which is extracted from the original one. Indeed, these fractions usually display simpler optical characteristics or narrower morphological distribution. In addition, in this case, the results reported in the literature, and therefore their interpretations, are quite variable. By size exclusion chromatography (SEC), Kang et al. [62] separated CD nanoparticles according to their size. They found that the emission depends on the fraction, although each fraction displays a non-tunable fluorescence. Following this, they claimed that the inhomogeneity and, therefore, the tunability, is due to size polydispersity. For this reason, they supported the idea of a quantum confinement effect which affects the origin of emission. On the contrary, Wen et al. [89], using the same fractionation method, isolated several fractions with different size, and two of them in particular were considered pure emitters (green and blue, respectively) (Figure 9). The smaller fraction emits green fluorescence and the larger emits blue light, behaviour which is completely in disagreement with a quantum confinement vision. Therefore, the authors associated the tunability of the as-prepared sample to a different form of heterogeneity, i.e., dot-to-dot fluctuations of the density and type of surface functional groups. Thus, rather than quantum confinement, these authors propose that differently-sized dots display variable optical properties as a consequence of their different surface-to-volume ratio [89]. This interpretation was recently confirmed by a work where SEC was combined for the first time with ultrafast spectroscopy to address the elusive origin of fluorescence tunability [173].

Another commonly used separation procedure is High Performance Liquid Chromatography (HPLC) $[25,92]$. The success of the technique is evident from the very different optical properties of the obtained fractions, although it is generally difficult to operate a selection based on a single structural property (size, polarity...). In Ref. [25], the subsets show diverse emission bands and the single fractions are non-tunable. According to this, the authors generically associated the origin of tunability to the inhomogeneity of nanoparticle charge and/or size. Fuyuno et al. [92], using the same technique on a sample of GQDs, accomplished the separation of the sample into fractions displaying different optical properties. Despite this, they did not observe the disappearance of tunability and, therefore, associated the latter with the presence of $\mathrm{sp}^{2}$ domains with different size and shape within each GQD.

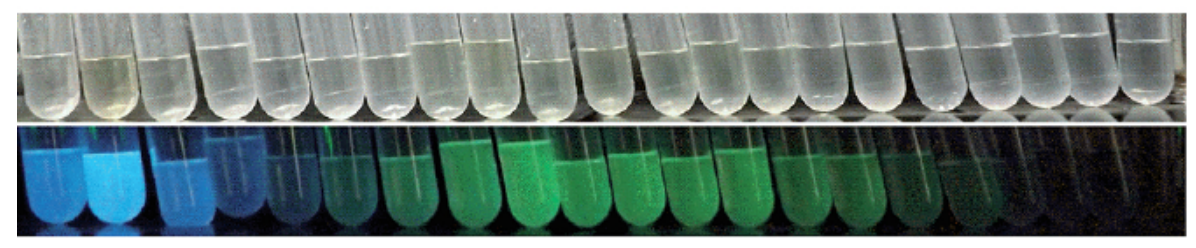

Figure 9. Products from a size exclusion chromatography procedure, as observed under daylight (top), or under UV light (bottom). Reproduced with permission from [89]. Copyright Royal Society of Chemistry, 2016.

Gel electrophoresis is another separation method by which it is possible to isolate fractions according to the surface charge. In addition, with this technique, the existing results in the literature are contradictory. In Ref. [106], this technique allowed for separating subsets of CDs emitting different colours according to their surface charge, in particular dots with the most negative charge on the surface were found to emit blue light. On the contrary, Ehrat et al. [196] did not succeed in the fractionation of different colored samples with the same method, and they separated a CD sample into different fractions which display the same emission band.

Despite these extremely contrasting results, most authors still agree to explain tunability as an effect of disorder. It is worth noting that a completely different explanation was proposed in one 
study based on the result of a solvatochromic investigation [180], where the authors found a very slow solvation mechanism which causes a redshift of the fluorescence spectrum progressing on a time scale comparable to that of fluorescence decay. This so-called red-edge effect violates Kasha's rule and therefore may explain fluorescence tunability because the relative population of different emissive states becomes dependent on the excitation energy. However, such a hypothesis of very slow solvation around the surface of CDs has been disputed by several later works, based on the direct observation of solvation dynamics on sub-nanosecond time scales [102,132].

\subsection{Interactions with the External Environment}

CD sensitivity to variations of external environment is very well-known. Many articles demonstrate that the fluorescence of CDs is sensitive to external agents in solution as ions or molecules [138,197], to solvent differences [180], or to changes in $\mathrm{pH}$ value [175]. This sensitivity is very useful in several applications, as explained in Section 2.3, but the fundamental mechanisms behind it are still unclear.

Most CDs are very rich of surface $-\mathrm{COOH}$ groups, which get negatively charged in solution. Therefore, the formation of complexes with positively-charged metal ions is favoured, and the observation of such interactions is particularly widespread in the literature. When metal cations such as $\mathrm{Hg}^{2+}, \mathrm{Cu}^{2+}, \mathrm{Fe}^{3+}$ are dispersed in a $\mathrm{CD}$ solution, they usually produce a quenching of $\mathrm{CDs}$ fluorescence. The most accepted explanation invokes an efficient electron transfer from photoexcited CDs to metal ions [138,198], which prevents the radiative recombination of photo-generated excitons. On one hand, this interaction is not surprising, being very similar to the well-known quenching action of several common cations on the fluorescence of many organic dyes [199]. On the other hand, the tendency of CDs to easily participate to such photo-induced electron transfer reactions endorses the attribution of CDs fluorescence to surface states. In fact, it suggests that the emission involves surface charge traps directly exposed to the solvent, considering that electron transfer generally occurs on very short spatial scales.

In the literature, spectroscopic evidence of these interactions are several and most of them are obtained by steady-state and time resolved spectroscopy (nanosecond to femtosecond) [132,138,175,198]. These works have demonstrated that, depending on cases, electron transfer can occur either statically or dynamically. Static quenching $[138,175,198]$ is associated with the formation of a relatively stable, non-luminescent CD-ion complex (Figure 10) [138], whereas dynamic quenching is mediated by collisions between CDs and diffusing metal ions in solution [198,200,201], which can be experimentally revealed by a reduction of the excited-state lifetime of CDs.
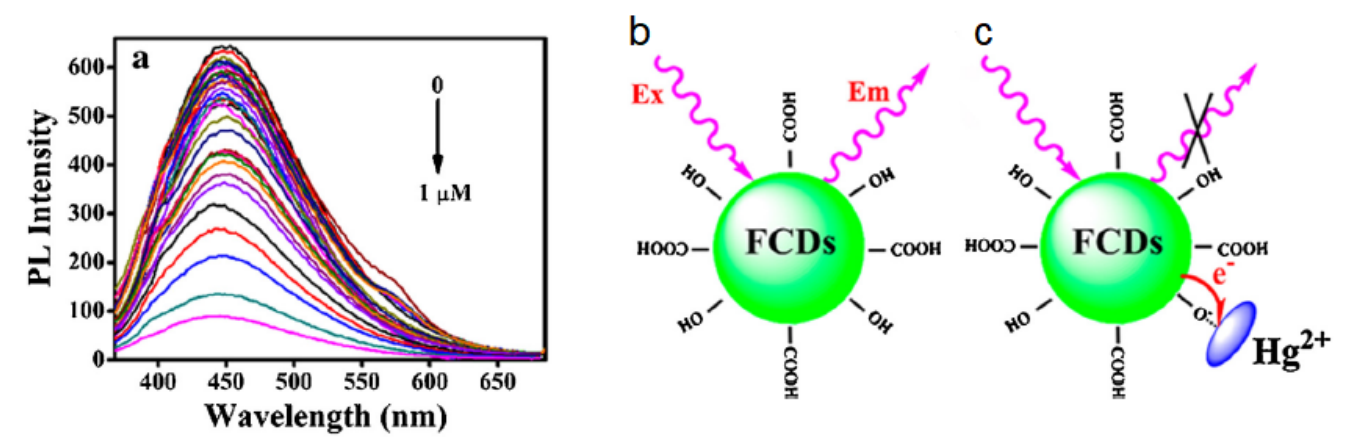

Figure 10. (a): emission spectra of CD solution with different amount of $\mathrm{Hg}^{2+}$ ions. (b,c): schematic illustration of fluorescence and quenching mechanisms, respectively. Reproduced with permission from [138]. Copyright Elsevier, 2012.

In general, the fluorescence of CDs usually responds to multiple metal cations, but some works $[202,203]$ have reported a selective quenching of CDs by specific ions, which is probably 
due to the specific binding interactions between certain CD surface groups with particular metals. Another recurrent finding in the literature is the selectivity of quenching by a copper ion with respect to zinc ion, which supports the idea of an electron transfer interaction. In fact, copper ions have an open-shell electronic configuration ([Ar] $\left.3 \mathrm{~d}^{9}\right)$ which can host an electron donated from the dot, while zinc ions have a full $\mathrm{d}$-shell and they are not expected to easily accept additional electrons [132,175].

In general, the ability of CDs to act as efficient photo-activated electron donors is rather well-established and not limited to the interaction with transition metal ions. In addition, depending on surface structure, CDs can also work as photo-excited electron acceptors. For instance, charge transfer dynamics are observed between CDs and organic molecules [197], or various types of metal complexes [204] or when CDs are adsorbed onto semiconductor surface [62]. This is the phenomenon which allows for using CDs as photosensitizers of semiconductors in photocatalytic devices.

The physical and chemical mechanisms underneath the charge transfer are not clear, as for instance the role of a specific surface structure in mediating the interaction between CD surfaces and a given ion. In addition, the dynamics of these processes are quite fast (picosecond or less) and they are invisible with standard spectroscopical methods, therefore ultrafast time-resolved techniques, still rare in the field, are necessary to go deeply inside the mechanisms of these interactions, and are being increasingly used in recent times. These studies are discussed in the next subsection.

When CDs are in contact with other electron donors (stronger than CDs), as in Refs. [197] or [204], they can act as electron acceptor and their fluorescence is quenched because a photoinduced electron transfer occurs from the external agent to the dots. The capability of CDs of behaving more efficiently as electron donors or acceptors is not well understood, but is likely related to their redox potential [132,205], which, in turn, depends on core and surface structures. To control this behaviour, which can be useful in photocatalytic or optoelectronic devices, Barman et al. [206] compared the behaviour of CDs subjected to n- or p-type doping. The electron transfer from the dot is favoured in the case of n-type doping (obtained with phosphorous), whereas CDs behave as electron acceptors (hole donors) when they are p-doped (by boron doping). Another way to control these properties is tailoring the surface of CDs in such a way to control their redox potential. Rigodanza and coworkers [205] did this with a reaction between CDs and different quinones, and demonstrated the promising electron transfer properties of CDs in particular surface conditions.

Besides the interactions with metal ions or molecules in solution, also solvent and $\mathrm{pH}$ have a crucial role in the properties of CDs. In particular, solvatochromic changes of the emission have been reported by several works $[31,43,180,207]$, and the solvent can influence the interaction between photoexcited CDs and various external systems $[197,202]$. Moreover, changes in $\mathrm{pH}$ value influence emission intensity [198], probably changing the charge state of surface groups [175], due to their acidic/basic character. Similar to the electron transfer interactions, these observations also tend to confirm the key role of surface states in the photo-cycle of CDs. Chandra et al. [175] demonstrate that CDs synthesized from different precursors are stable in diverse $\mathrm{pH}$ intervals and, consequently, the emission is maximum at different pHs. This is caused by the presence of various groups on the surface as, for instance, $-\mathrm{COOH}$ and $-\mathrm{NH}_{2}$, which have very different acid-base properties. Another example is reported in Ref. [198] where a great amount of $\mathrm{H}^{+}$ions in solution is found to modify the emission. Here, the authors supposed that $\mathrm{H}^{+}$ions can protonate pyridinic $\mathrm{N}$ atoms on the surface of the dot, supposedly responsible for the emission. Then, when the system is photoexcited, a proton transfer supposedly occurs from pyridinic $\mathrm{N}$ to the carbon structure which blocks the emission process. Solvation usually modifies CDs emission both through non-specific and site-specific interaction. In fact, depending on cases, CDs can be either sensitive to the polarity of the solvent, or to its capacity to form a hydrogen bond, or to both. Because CD surfaces are rich in HB acceptors such as carboxyilic groups, their capability to accept a hydrogen bond from a protic solvent can be absolutely crucial in the stabilization of the excited state, hence in determining the emission peak position $[43,208,209]$. Solvation studies with the use of steady state and time resolved nanosecond 
spectroscopy demonstrate these effects through the dependence of the emission band on the polarity of the solvent $[43,102,197,210]$, as well as a solvent-driven modulation of the non-radiative decay rates, hence the quantum yield [43,211]. Femtosecond studies, still rare for CDs, are needed to directly observe the undergoing solvation dynamics, which occurs on the picosecond and sub-picosecond scale [132,207]. In some cases, CDs display a very complex and irregular solvent response [32,102], which was attributed it to the coexistence of hydrophobic and hydrophilic groups on their surface (Figure 11). However, depending on their surface structures, CDs can also display a surprisingly simple solvent response, which can be used as a sensitive probe of the local polarity of the surrounding environment, though a regular dependence of the emission peak from the Dimroth-Reichardt $E_{T}^{N}$ solvent polarity parameter [43].
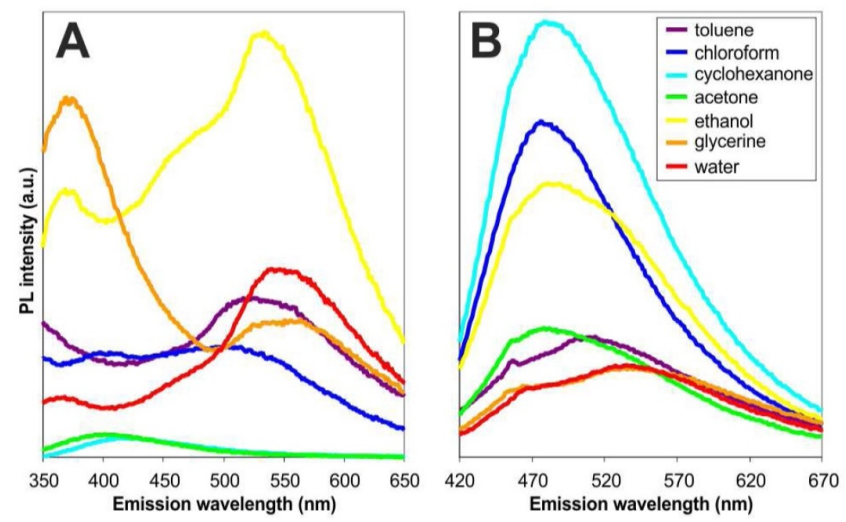

Figure 11. Emission spectra of CDs in different solvents excited at $290 \mathrm{~nm}$ (A) and $400 \mathrm{~nm}$ (B). Reproduced with permission from [32]. Copyright American Chemical Society, 2013.

\subsection{Ultrafast Spectroscopy on Carbon Nanodots}

Ultrafast spectroscopy is a powerful tool to investigate in real-time electronic and vibrational processes with ps $\left(10^{-12} \mathrm{~s}\right)$ and $\mathrm{fs}\left(10^{-15} \mathrm{~s}\right)$ time resolution [212]. In general, these techniques are mandatory to map in full detail the photocycle of any physical system. Indeed, several dynamics can occur on ps or sub-ps time scale, including the energy cascade from the initially-excited state to the emissive state, solvation and hydrogen bonding dynamics, charge and energy transfer, and fluorescence quenching. By ultrafast techniques, it is possible to study in real time these mechanisms, which would be hidden in the steady-state spectra. Thus, this kind of experiments allows to map the relaxation channels which either lead to a long-lived emission or to a non-radiative recombination which prevents the formation of a fluorescent state. Ultrafast investigations on CDs recently started to attract interests by a few groups who use transient absorption (TA) spectroscopy [109,132,173,207,213], and fluorescence upconversion (FLUC) [214-216] to understand the photocycle of pristine CDs or their interactions with other nanoparticles, ions, or molecules. The aim is to overcome the severe limitations of previous studies mostly based on steady-state optical methods. TA and FLUC spectroscopies rely on measuring the photoinduced variations of the sample absorption spectrum, or the spontaneous emission of the sample, respectively, as a function of time and wavelength. Both techniques allow for elucidating the dynamics of a photoexcited system and the interactions with the external environment, with femtosecond time resolution.

Wang et al. [214] proposed a model for the emission of GQDs, based on the combined use of TA and FLUC. Their GQDs are characterized by two different emissions characterized by two separate lifetimes. The former is long-lived (few ns) and is responsible for the steady state emission, associated with the presence of functional groups at the edge of GQDs; the lifetime of the latter is very short (less than $2 \mathrm{ps)}$ ) and related to a band-to-band transition, described by the authors as a dark intrinsic state. Ultrafast techniques turn out to be the only way to observe the existence of 
these short-lived transitions, therefore to disentangle the role of band-to-band from edge transitions. In this case, the two types of emissions seem to proceed independently from each other, without any crosstalk between core and edge states. In addition, the population of the excited state appears to be instantaneous upon photo-excitation.

Opposite results were found by other works, where various forms of excitation transfer from core to surface were proposed $[54,107,108,166,178,179]$. For example, Strauss et al. [179] found that the population of the excited state occurs in tens of picoseconds from initial photo-excitation, probably through an energy transfer from the core. Other works, however, proposed these dynamics to be much faster, being completed within 400 fs [54]. The TA experiment presented by Lu et al. [107,108] discussed in more detail the interplay between core and surface. In fact, they disentangled two parallel relaxation channels which contribute to the population, from the photoexcited carbon core, of two different types of surface states: one which recombines in a non-radiative way and another one which is strongly emissive and detectable in steady-state experiments. Thereby, these results directly suggest the existence of an interplay between the carbon core and the surface states which contribute to the emission. By FLUC experiments, Wen et al. [215] conducted a study of the dynamics of charge carriers in photo-excited CDs, trying to compare them to the well-known dynamics within photoexcited semiconductor nanoparticles [162]. In their study, they identified time scales related to optical phonon scattering ( $<5 \mathrm{ps})$, acoustic phonon scattering (50 ps) and exciton recombination (1.5 ns). Moreover, they identified a fast component of $400 \mathrm{fs}$ which is attributed to surface trapping of electrons from the core into surface states.

As already mentioned, solvation dynamics at the surface of CDs is expected to occur on sub-nanosecond time scales, as usually observed in molecular dyes. Therefore, femtosecond methods are mandatory to study these relaxation effects. Studies of $C D$ solvation are still very rare. Jing et al. [207], recently observed solvation relaxation for CDs in different solvents, and attributed these dynamics to dipole-dipole interaction between $\mathrm{CDs}$ and solvent molecules.

Besides the intrinsic photocycle, ultrafast methods have also been used to address the fundamental mechanisms of charge transfer from or to CDs-for example when they are coupled to other materials as graphene oxide [216] or metal complexes [204]. As mentioned in Section 3.3, the emission of CDs is commonly quenched by interaction with a variety of external agents. This effect is tentatively associated with electron transfer from the dot to the coupled system or the other way around. Very few works used femtosecond methods to address the problem of electron transfer dynamics from/to CDs to/from various coupled systems. For instance, in Ref. [216], the authors studied CD-graphene oxide (GO) nanocomposites and found a time constant of $400 \mathrm{fs}$ for the electron transfer from CDs to GO. Another work [204] dealt with the interactions between CDs and iridium-ruthenium metal complexes, from which the authors identified two time constants of $\approx 1$ ps and $\approx 20$ ps associated with charge transfer from the metal complex to the CDs excited state. A recent study addressed for the first time by femtosecond methods the interaction dynamics between $\mathrm{CD}$ and copper ions, an archetipal oxidant for $\mathrm{CDs}$, and directly observed the dynamics of the electron transfer reactions, occurring on two time scales of $0.2 \mathrm{ps}$ and $2.0 \mathrm{ps}$ [132]. Interestingly, it was found that these reactions are driven by the local rearrangment of the solvent around the anchoring site of the ion on the CD surface, suggesting again a key role of the solvent in determining the photophysics of these systems.

Combining CDs with other materials in solar cells or photocatalytic devices changes the efficiency of the device, increasing or decreasing it. Some authors used femtosecond spectroscopy to investigate the optical response of these devices $[109,155,213]$, or of the component materials used in them [216-219]. It is worth reporting here the comparison between two extreme situations. Tetsuka et al. [213] used a sample of nitrogen-functionalized GQDs as a layer within a perovskite solar cell. Using femtosecond TA, they established the speed up in the electron extraction rate from $\approx 300 \mathrm{ps}$ to $\approx 50$ ps caused by the addition of GQDs, as a consequence of which GQDs lead to an increase of the power conversion efficiency. On the other extreme, Margraf et al. [155] demonstrated that the use of 
CDs as sensitizers in mesoscopic solar cells reduces the performance of the solar cells and attributed this to the non-ideal balance between the charge recombination and the regeneration processes.

Last but not least, femtosecond methods are not only useful to study the fundamental photo-cycle of CDs, but also to address the relation between disorder and fluorescence tunability, providing a complementary approach with respect to single-molecule and fractionation experiments discussed in Section 3.2. Recently, femtosecond hole burning experiments [173], allowed for breaking into the structureless electronic absorption spectra of CDs and reveal the true, underlying homogeneous absorption lineshapes. Combined with SEC, these experiments allowed for explaining CD fluorescence tunability as a photo-selection effect across a family of transitions with continuously variable energies (Figure 12). This dot-to-dot spectroscopic variability was attributed to the fluctuating surface structures of the ultra-small dots, ruling out again any role of quantum confinement in the emission mechanism of these CDs.

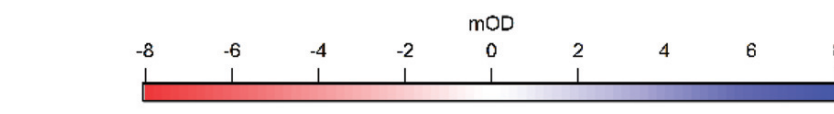

(a) $\lambda=495 \mathrm{~nm}$, (b) $\lambda=520 \mathrm{~nm}$, (c) $\lambda=537 \mathrm{~nm}$, (d) $\lambda=554 \mathrm{~nm}$, (e) $\lambda=570 \mathrm{~nm}$
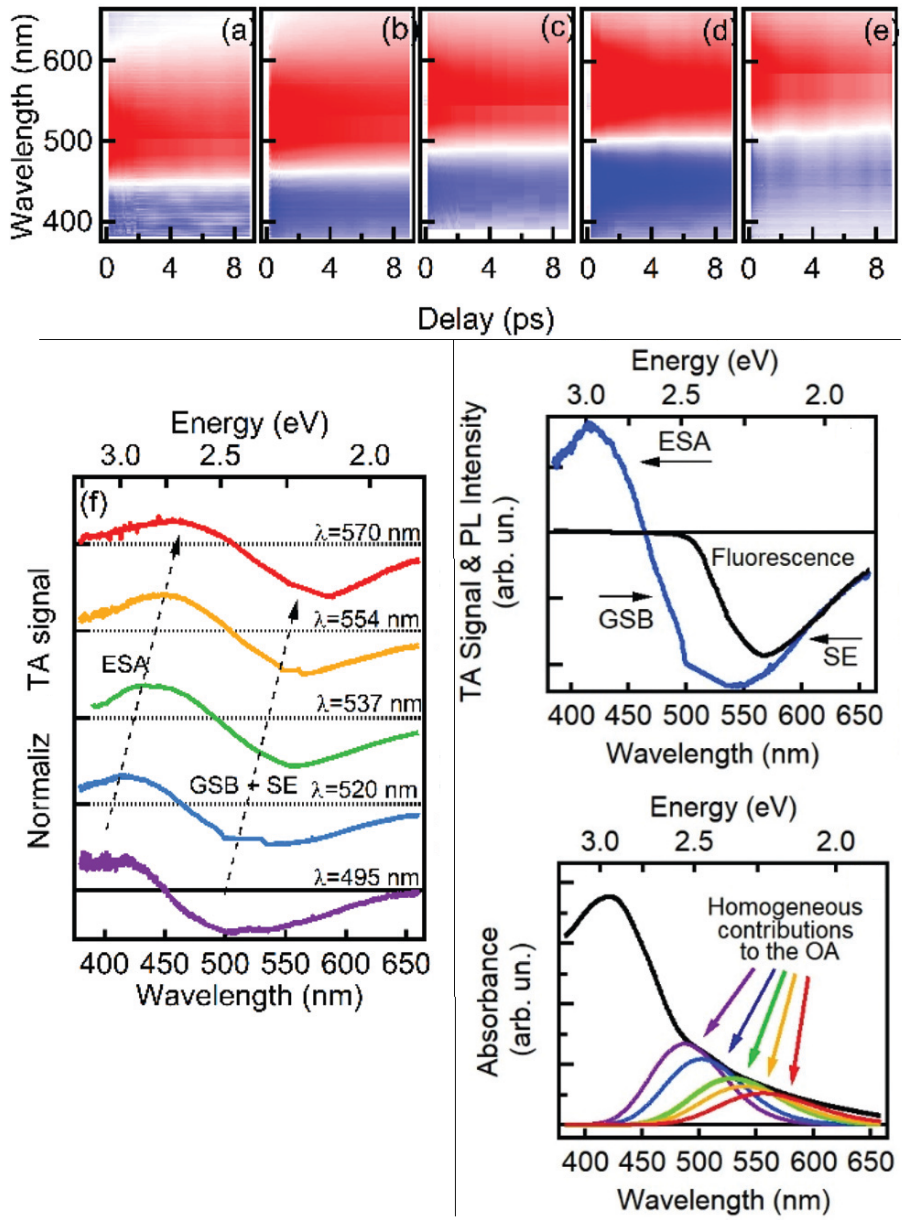

Figure 12. (top): femtosecond TA data excited at different wavelengths. (bottom left): data recorded at 50 ps from photo-excitation, showing the hole burning within the optical absorption band, and the photoselection across a family of transition with continuously variable energies. (middle right): decomposition of the TA data in contributions due to ground state bleaching (GSB), excited-state absorption (ESA) and stimulated emission (SE). The SE is compared with the steady-state fluorescence signal. (bottom right): comparison between steady-state optical absorption (OA) and individual homogeneous contributions obtained from hole burning data. Reproduced with permission from [173]. Copyright Royal Society of Chemistry, 2018. 


\section{Conclusions}

After more than a decade of intense debate, the problem of understanding the fundamental photophysics of CDs is still open, made particularly difficult by the large variability of CD structures. The existing data overall indicate that $C D$ optical responses cannot be described within a simple and unified paradigm. In fact, the wide structural variability of CDs synthesized through different routes entails a range of different electronic properties and variable behaviours upon photo-excitations. However, one should keep in mind that the remarkable diversity of CDs synthesized by different routes remains one of their key strengths in tailoring them for multiple applications.

The "classical" interpretations of CD fluorescence invoke a combination of transitions involving molecular-like surface states, states related to surface passivating groups, and conjugated $\mathrm{sp}^{2}$ domains within the carbogenic core. Today, it should be recognized that these different mechanisms are probably all possible, although the unique interplay betwen electronic states of different nature is structure-dependent and uniquely determined for each sub-type of CD.

Anyway, recent works have achieved important steps forward in our current understanding of these nanosystems, by deploying a range of advanced methods from single-molecule microscopy to femtosecond time-resolved spectroscopy. For instance, it has been conclusively clarified that the characteristic fluorescence "tunability" of CDs is an effect of disorder, mostly due to dot-to-dot fluctuations of the surface structure. Furthermore, the crucial role of surface trap states, populated by spontaneous charge separation after photo-excitation, is now well-established in the literature. Indeed, recent work has provided direct evidence, in several significant cases, of the very fundamental dynamics that bring CDs from the initially excited state to the final outcome of the photocycle, either fluorescence or a relevant photochemical process.

Despite these advances, plenty of work remains to be done. In particular, the ability to reliably foresee how a given CD structure will yield a specific photo-physical behaviour is still beyond our reach. Such a limitation, combined with the enduring difficulty of synthesizing CDs with precisely controlled structures, still hinders their full control and optimization in a number of applications. Thus, the main challenge to be overcome in the field remains, achieving a comprehensive understanding of how the optical response of CDs can be traced back to specific, and tightly controlled, microcopic structures. Only by fulfilling this task will it be possible to achieve the complete control of CDs and fully exploit their large technological potential.

Author Contributions: Writing-Original Draft Preparation, A.S.; Writing-Review \& Editing, A.S., A.C., F.M.; Supervision, A.C., F.M.

Funding: This research received no external funding.

Acknowledgments: The authors wish to thank all members of the Laboratory "R. Boscaino" of Advanced Materials-University of Palermo, Italy, and of the Ultrafast Molecular Spectroscopy Lab-University of Bern (Switzerland), for support and stimulating discussions. A.C. thanks the Swiss SNSF through the NCCR MUST and SNSF project n. 200021_172696.

Conflicts of Interest: The authors declare no conflict of interest.

\section{References}

1. Sun, Y.; Zhou, B.; Lin, Y.; Wang, W.; Fernando, K.A.S.; Pathak, P.; Meziani, M.J.; Harruff, B.A.; Wang, X.; Wang, H.; et al. Quantum-Sized Carbon Dots for Bright and Colorful Photoluminescence. J. Am. Chem. Soc. 2006, 128, 7756-7757. [CrossRef] [PubMed]

2. Xu, X.; Ray, R.; Gu, Y.; Ploehn, H.J.; Gearheart, L.; Raker, K.; Scrivens, W.A. Electrophoretic Analysis and Purification of Fluorescent Single-Walled Carbon Nanotube Fragments. J. Am. Chem. Soc. 2004, 126, 12736-12737. [CrossRef] [PubMed]

3. Cayuela, A.; Soriano, M.L.; Carrillo-Carrion, C.; Valcarcel, M. Semiconductor and carbon-based fluorescent nanodots: The need for consistency. Chem. Commun. 2016, 52, 1311-1326. [CrossRef] [PubMed]

4. Li, H.; Kang, Z.; Liu, Y.; Lee, S.T. Carbon nanodots: Synthesis, properties and applications. J. Mater. Chem. 2012, 22, 24230-24253. [CrossRef] 
5. Nguyen, V.; Si, J.; Yan, L.; Hou, X. Direct demonstration of photoluminescence originated from surface functional groups in carbon nanodots. Carbon 2016, 108, 268-273. [CrossRef]

6. Pan, L.; Sun, S.; Zhang, A.; Jiang, K.; Zhang, L.; Dong, C.; Huang, Q.; Wu, A.; Lin, H. Truly Fluorescent Excitation-Dependent Carbon Dots and Their Applications in Multicolor Cellular Imaging and Multidimensional Sensing. Adv. Mater. 2015, 27, 7782-7787. [CrossRef] [PubMed]

7. Cayuela, A.; Soriano, M.L.; Valcàrcel, M. Photoluminescent carbon dot sensor for carboxylated multiwalled carbon nanotube detection in river water. Sens. Actuators 2015, 207, 596-601. [CrossRef]

8. Zhou, J.; Yang, Y.; Zhang, C.Y. A low-temperature solid-phase method to synthesize highly fluorescent carbon nitride dots with tunable emission. Chem. Commun. 2013, 49, 8605-8607. [CrossRef]

9. Rong, M.; Song, X.; Zhao, T.; Yao, Q.; Wang, Y.; Chen, X. Synthesis of highly fluorescent P,O-g- $\mathrm{C}_{3} \mathrm{~N}_{4}$ nanodots for the label-free detection of $\mathrm{Cu}^{2+}$ and acetylcholinesterase activity. J. Mater. Chem. C 2015, 3, 10916-10924. [CrossRef]

10. Sciortino, A.; Mauro, N.; Buscarino, G.; Sciortino, L.; Popescu, R.; Schneider, R.; Giammona, G.; Gerthsen, D.; Cannas, M.; Messina, F. $\beta-C_{3} N_{4}$ Nanocrystals: Carbon Dots with Extraordinary Morphological, Structural, and Optical Homogeneity. Chem. Mater. 2018, 30, 1695-1700. [CrossRef]

11. Shinde, D.B.; Pillai, V.K. Electrochemical Preparation of Luminescent Graphene Quantum Dots from Multiwalled Carbon Nanotubes. Chem. Eur. J. 2012, 18, 12522-12528. [CrossRef] [PubMed]

12. Zhu, H.; Wang, X.; Li, Y.; Wang, Z.; Yang, F.; Yang, X. Microwave synthesis of fluorescent carbon nanoparticles with electrochemiluminescence properties. Chem. Commun. 2009, 34, 5118-5120. [CrossRef] [PubMed]

13. Papagiannouli, I.; Patanen, M.; Blanchet, V.; Bozek, J.D.; de Anda Villa, M.; Huttula, M.; Kokkonen, E.; Lamour, E.; Mevel, E.; Pelimanni, E.; et al. Depth Profiling of the Chemical Composition of Free-Standing Carbon Dots Using X-ray Photoelectron Spectroscopy. J. Phys. Chem. C 2018, 122, 14889-14897. [CrossRef]

14. Bourlinos, A.B.; Stassinopoulos, A.; Anglos, D.; Zboril, R.; Karakassides, M.; Giannelis, E.P. Surface Functionalized Carbogenic Quantum Dots. Small 2008, 4, 455-458. [CrossRef] [PubMed]

15. Panniello, A.; Di Mauro, A.E.; Fanizza, E.; Depalo, N.; Agostiano, A.; Curri, M.L.; Striccoli, M. Luminescent Oil-Soluble Carbon Dots toward White Light Emission: A Spectroscopic Study. J. Phys. Chem. C 2018, 122, 839-849. [CrossRef]

16. Zhou, J.; Booker, C.; Li, R.; Zhou, X.; Sham, T.K.; Sun, X.; Ding, Z. An Electrochemical Avenue to Blue Luminescent Nanocrystals from Multiwalled Carbon Nanotubes (MWCNTs). J. Am. Chem. Soc. 2007, 129, 744-745. [CrossRef] [PubMed]

17. Miao, X.; Yan, X.; Qu, D.; Li, D.; Tao, F.F.; Sun, Z. Red Emissive Sulfur, Nitrogen Codoped Carbon Dots and Their Application in Ion Detection and Theraonostics. ACS Appl. Mater. Interfaces 2017, 9, 18549-18556. [CrossRef]

18. Zhang, Y.; Hu, Y.; Lin, J.; Fan, Y.; Li, Y.; Lv, Y.; Liu, X. Excitation wavelength independence: Toward low-threshold amplified spontaneous emission from carbon nanodot. ACS Appl. Mater. Interfaces 2016, 8, 25454-25460. [CrossRef]

19. Gude, V.; Das, A.; Chatterjee, T.; Mandal, P.K. Molecular origin of photoluminescence of carbon dots: Aggregation-induced orange-red emission. Phys. Chem. Chem. Phys. 2016, 18, 28274-28280. [CrossRef]

20. Liu, S.; Tian, J.; Wang, L.; Zhang, Y.; Qin, X.; Luo, Y.; Asiri, A.M.; Al-Youbi, A.O.; Sun, X. Hydrothermal Treatment of Grass: A Low-Cost, Green Route to Nitrogen-Doped, Carbon-Rich, Photoluminescent Polymer Nanodots as an Effective Fluorescent Sensing Platform for Label-Free Detection of Cu(II) Ions. Adv. Mater. 2012, 24, 2037-2041. [CrossRef]

21. Huang, H.; Lv, J.J.; Zhou, D.L.; Bao, N.; Xu, Y.; Wang, A.J.; Feng, J.J. One-pot green synthesis of nitrogen-doped carbon nanoparticles as fluorescent probes for mercury ions. RSC Adv. 2013, 3, 21691-21696. [CrossRef]

22. Xu, Q.; Pu, P.; Zhao, J.; Dong, C.; Gao, C.; Chen, Y.; Chen, J.; Liu, Y.; Zhou, H. Preparation of highly photoluminescent sulfur-doped carbon dots for Fe(iii) detection. J. Mater. Chem. A 2015, 3, 542-546. [CrossRef]

23. Sciortino, A.; Cayuela, A.; Soriano, M.L.; Gelardi, F.M.; Cannas, M.; Valcarcel, M.; Messina, F. Different natures of surface electronic transitions of carbon nanoparticles. Phys. Chem. Chem. Phys. 2017, 19, 22670-22677. [CrossRef] [PubMed] 
24. Wang, X.; Wang, S.T.; Lu, F.; Meziani, M.J.; Tian, L.; Sun, K.W.; Bloodgood, M.A.; Sun, Y.P. Bandgap-like strong fluorescence in functionalized carbon nanoparticles. Angew. Chem. Int. Ed. 2010, 122, 5438-5442. [CrossRef]

25. Vinci, J.C.; Ferrer, I.M.; Seedhouse, S.J.; Bourdon, A.K.; Reynard, J.M.; Foster, B.A.; Bright, F.V.; Colòn, L.A. Hidden properties of carbon dots revealsed after HPCL fractionation. J. Phys. Chem. Lett. 2013, 4, $239-243$. [CrossRef] [PubMed]

26. Zhu, S.; Meng, Q.; Wang, L.; Zhang, J.; Song, Y.; Jin, H.; Zhang, K.; Sun, H.; Wang, H.; Yang, B. Highly Photoluminescent Carbon dots for multicolor patterning, sensors and bioimaging. Angew. Chem. Int. Ed. 2013, 125, 4045-4049. [CrossRef]

27. Hou, J.; Wang, W.; Zhou, T.; Wang, B.; Li, H.; Ding, L. Synthesis and Formation Mechanistic Investigation of Nitrogen- Doped Carbon-Dots with High Quantum Yield and Yellowish-Green Fluorescence. Nanoscale 2016, 8, 11185-11193. [CrossRef] [PubMed]

28. Qiao, Z.A.; Wang, Y.; Gao, Y.; Li, H.; Dai, T.; Liu, Y.; Huo, Q. Commercially activated carbon as the source for producing multicolor photoluminescent carbon dots by chemical oxidation. Chem. Commun. 2010, 46, 8812-8814. [CrossRef]

29. Liu, C.; Zhang, P.; Tian, F.; Li, W.; Li, F.; Liu, W. One-step synthesis of surface passivated carbon nanodots by microwave assisted pyrolysis for enhanced multicolor photoluminescence and bioimaging. J. Mater. Chem. 2011, 21, 13163-13167. [CrossRef]

30. Bourlinos, A.B.; Zbořil, R.; Petr, J.; Bakandritsos, A.; Krysmann, M.; Giannelis, E.P. Luminescent Surface Quaternized Carbon Dots. Chem. Mater. 2012, 24, 6-8. [CrossRef]

31. Pan, D.; Zhang, J.; Li, Z.; Wu, C.; Yan, X.; Wu, M. Observation of pH, solvent-, spin-, and excitation-dependent blue photoluminescence from carbon nanoparticles. Chem. Commun. 2010, 46, 3681-3683. [CrossRef] [PubMed]

32. Kozák, O.; Datta, K.K.; Greplová, M.; Ranc, V.; Kašlík, J.; Zbořil, R. Surfactant-Derived Amphiphilic Carbon Dots with Tunable Photoluminescence. J. Phys. Chem. C 2013, 117, 24991-24996. [CrossRef]

33. Zhang, S.; Li, J.; Zeng, M.; Xu, J.; Wang, X.; Hu, W. Polymer nanodots of graphitic carbon nitride as effective fluorescent probes for the detection of $\mathrm{Fe}^{3+}$ and $\mathrm{Cu}^{2+}$ ions. Nanoscale 2014, 6, 4157-4162. [CrossRef] [PubMed]

34. Liu, M.; Xu, Y.; Niu, F.; Gooding, J.J.; Liu, J. Carbon quantum dots directly generated from electrochemical oxidation of graphite electrodes in alkaline alcohols and the applications for specific ferric ion detection and cell imaging. Analyst 2016, 141, 2657-2664. [CrossRef] [PubMed]

35. Wang, C.; Xu, Z.; Zhang, C. Polyethyleneimine-Functionalized Fluorescent Carbon Dots: Water Stability, pH Sensing, and Cellular Imaging. ChemNanoMat 2015, 1, 122-127. [CrossRef]

36. Cayuela, A.; Soriano, M.L.; Carriòn, M.C.; Valcàrcel, M. Functionalized carbon dots as sensors for gold nanoparticles in spiked samples: Formation of nanohybrids. Anal. Chim. Acta 2014, 820, 133-138. [CrossRef] [PubMed]

37. Zhou, D.; Li, D.; Jing, P.; Zhai, Y.; Shen, D.; Qu, S.; Rogach, A.L. Conquering Aggregation-Induced Solid-State Luminescence Quenching of Carbon Dots through a Carbon Dots-Triggered Silica Gelation Process. Chem. Mater. 2017, 29, 1779-1787. [CrossRef]

38. Chen, Y.; Zheng, M.; Xiao, Y.; Dong, H.; Zhang, H.; Zhuang, J.; Hu, H.; Lei, B.; Liu, Y. A Self-quenching-resistan Carbon-dot powder with tunable solid-state fluorescence and construction of dual-fluorescence morphologies for white light-emission. Adv. Mater. 2015, 28, 312-318. [CrossRef]

39. LeCroy, G.E.; Messina, F.; Sciortino, A.; Bunker, C.E.; Wang, P.; Shiral, K.A.F.; Sun, Y.P. Characteristic Excitation Wavelength Dependence of Fluorescence Emissions in Carbon “Quantum” Dots. J. Phys. Chem. C 2017, 121, 28180-28186. [CrossRef]

40. Shi, Y.; Li, C.; Liu, Z.; Zhu, J.; Yang, J.; Hu, X. Facile synthesis of fluorescent carbon dots for determination of curcumin based on fluorescence resonance energy transfer. RSC Adv. 2015, 5, 64790-64796. [CrossRef]

41. Muhammad, M.; Baig, F.; Chen, Y.C. Bright carbon dots as fluorescence sensing agents for bacteria and curcumin. J. Colloid Interface Sci. 2017, 501, 341-349.

42. Wu, X.; Song, Y.; Yan, X.; Zhu, C.; Ma, Y.; Du, D.; Lin, Y. Carbon quantum dots as fluorescence resonance energy transfer sensors for organophosphate pesticides determination. Biosens. Bioelectron. 2017, 94, $292-297$. [CrossRef] [PubMed] 
43. Sciortino, A.; Marino, E.; Dam, B.V.; Schall, P.; Cannas, M.; Messina, F. Solvatochromism Unravels the Emission Mechanism of Carbon Nanodots. J. Phys. Chem. Lett. 2016, 7, 3419-3423. [CrossRef] [PubMed]

44. Zhu, S.; Song, Y.; Zhao, X.; Shao, J.; Zhang, J.; Yang, B. The photoluminescence mechanism in carbon dots (graphene quantum dots, carbon nanodots, and polymer dots): Current state and future perspective. Nano Res. 2015, 8, 355-381. [CrossRef]

45. Essner, J.B.; Baker, G.A. The emerging roles of carbon dots in solar photovoltaics: A critical review. Environ. Sci. Nano 2017, 4, 1216-1263. [CrossRef]

46. Malfatti, L.; Innocenzi, P. Sol-Gel Chemistry for Carbon Dots. Chem. Rec. 2018, 18, 1192-1202. [CrossRef]

47. Lim, S.Y.; Shen, W.; Gao, Z. Carbon quantum dots and their applications. Chem. Soc. Rev. 2015, 44, 362-381. [CrossRef]

48. Wang, Y.; Zhu, Y.; Yu, S.; Jiang, C. Fluorescent carbon dots: Rational synthesis, tunable optical properties and analytical applications. RSC Adv. 2017, 7, 40973-40989. [CrossRef]

49. Wang, R.; Lu, K.Q.; Tang, Z.R.; Xu, Y.J. Recent progress in carbon quantum dots: Synthesis, properties and applications in photocatalysis. J. Mater. Chem. A 2017, 5, 3717-3734. [CrossRef]

50. Wu, Z.L.; Liu, Z.X.; Yuan, Y.H. Carbon dots: Materials, synthesis, properties and approaches to long-wavelength and multicolor emission. J. Mater. Chem. B 2017, 5, 3794-3809. [CrossRef]

51. Choi, Y.; Choi, Y.; Kwon, O.H.; Kim, B.S. Carbon Dots: Bottom-Up Syntheses, Properties, and Light-Harvesting Applications. Chem. Asian J. 2018, 13, 586-598. [CrossRef] [PubMed]

52. De, B.; Karak, N. Recent progress in carbon dot-metal based nanohybrids for photochemical and electrochemical applications. J. Mater. Chem. A 2017, 5, 1826-1859. [CrossRef]

53. Qu, S.; Wang, X.; Lu, Q.; Liu, X.; Wang, L. A Biocompatible Fluorescent Ink Based on Water-Soluble Luminescent Carbon Nanodots. Angew. Chem. Int. Ed. 2012, 51, 12215-12218. [CrossRef] [PubMed]

54. Sui, L.; Jin, W.; Li, S.; Liu, D.; Jiang, Y.; Chen, A.; Liu, H.; Shi, Y.; Ding, D.; Jin, M. Ultrafast carrier dynamics of carbon nanodots in different $\mathrm{pH}$ environments. Phys. Chem. Chem. Phys. 2016, 18, 3838-3845. [CrossRef] [PubMed]

55. Wang, L.; Bi, Y.; Gao, J.; Li, Y.; Ding, H.; Ding, L. Carbon dots based turn-on fluorescent probes for the sensitive determination of glyphosate in environmental water samples. RSC Adv. 2016, 6, 85820-85828. [CrossRef]

56. LeCroy, G.E.; Sonkar, S.K.; Yang, F.; Veca, L.M.; Wang, P.; Tackett, K.N.; Yu, J.J.; Vasile, E.; Qian, H.; Liu, Y.; et al. Toward Structurally Defined Carbon Dots as Ultracompact Fluorescent Probes. ACS Nano 2014, 8, 4522-4529. [CrossRef] [PubMed]

57. Amendola, V.; Meneghetti, M. What controls the composition and the structure of nanomaterials generated by laser ablation in liquid solution? Phys. Chem. Chem. Phys. 2013, 15, 3027-3046. [CrossRef]

58. Suda, Y.; Ono, T.; Akazawa, M.; Sakai, Y.; Tsujino, Y.; Homma, N. Preparation of carbon nanoparticles by plasma-assisted pulsed laser deposition method-size and binding energy dependence on ambient gas pressure and plasma condition. Thin Solid Films 2002, 415, 15-20. [CrossRef]

59. Hu, S.; Liu, J.; Yang, J.; Wang, Y.; Cao, S. Laser synthesis and size tailor of carbon quantum dots. J. Nanopart. Res. 2011, 13, 7247-7252. [CrossRef]

60. Reyes, D.; Camacho, M.; Camacho, M.; Mayorga, M.; Weathers, D.; Salamo, G.; Wang, Z.; Neogi, A. Laser Ablated Carbon Nanodots for Light Emission. Nano Res. Lett. 2016, 11, 424. [CrossRef]

61. Therese, G.H.A.; Kamath, P.V. Electrochemical Synthesis of Metal Oxides and Hydroxides. Chem. Mater. 2000, 12, 1195-1204. [CrossRef]

62. Li, H.; He, X.; Kang, Z.; Huang, H.; Liu, Y.; Liu, J.; Lian, S.; Tsang, C.H.A.; Yang, X.; Lee, S.T. Water-Soluble Fluorescent carbon quantum dots and photocatalyst design. Angew. Chem. Int. Ed. 2010, 49, 4430-4434. [CrossRef] [PubMed]

63. Bao, L.; Zhang, Z.L.; Tian, Z.Q.; Zhang, L.; Liu, C.; Lin, Y.; Qi, B.; Pang, D.W. Electrochemical tuning of luminescent carbon nanodots: From preparation to luminescence mechanism. Adv. Mater. 2011, 23, 5801-5806. [CrossRef] [PubMed]

64. Sahu, S.; Behera, B.; Maiti, T.K.; Mohapatra, S. Simple one-step synthesis of highly luminescent carbon dots from orange juice: Application as excellent bio-imaging agents. Chem. Commun. 2012, 48, 8835-8837. [CrossRef] [PubMed] 
65. Wang, L.; Wang, Y.; Xu, T.; Liao, H.; Yao, C.; Liu, Y.; Li, Z.; Chen, Z.; Pan, D.; Sun, L.; et al. Gram-scale synthesis of single-crystalline graphene quantum dots with superior optical properties. Nat. Commun. 2014, 5, 5357. [CrossRef] [PubMed]

66. Liu, Q.; Guo, B.; Rao, Z.; Zhang, B.; Gong, J.R. Strong Two-Photon-Induced Fluorescence from Photostable, Biocompatible Nitrogen-Doped Graphene Quantum Dots for Cellular and Deep-Tissue Imaging. Nano Lett. 2013, 13, 2436-2441. [CrossRef]

67. Guan, W.; Gu, W.; Ye, L.; Guo, C.; Su, S.; Xu, P.; Xue, M. Microwave-assisted polyol synthesis of carbon nitride dots from folic acid for cell imaging. Int. J. Nanomed. 2014, 9, 5071-5078.

68. Sciortino, L.; Sciortino, A.; Popescu, R.; Schneider, R.; Gerthsen, D.; Agnello, S.; Cannas, M.; Messina, F. Tailoring the Emission Color of Carbon Dots through Nitrogen-Induced Changes of Their Crystalline Structure. J. Phys. Chem. C 2018, 122, 19897-19903. [CrossRef]

69. Carbonaro, C.M.; Chiriu, D.; Stagi, L.; Casula, M.F.; Thakkar, S.V.; Malfatti, L.; Suzuki, K.; Ricci, P.C.; Corpino, R. Carbon Dots in Water and Mesoporous Matrix: Chasing the Origin of their Photoluminescence. J. Phys. Chem. C 2018, 122, 25638-25650. [CrossRef]

70. Wang, D.; Wang, X.; Guo, Y.; Liu, W.; Qin, W. Luminescent properties of milk carbon dots and their sulphur and nitrogen doped analogues. RSC Adv. 2014, 4, 51658-51665. [CrossRef]

71. Travlou, N.A.; Secor, J.; Bandosz, T.J. Highly luminescent S-doped carbon dots for the selective detection of ammonia. Carbon 2017, 114, 544-556. [CrossRef]

72. Rizzo, C.; Arcudi, F.; Đorđević, L.; Dintcheva, N.T.; Noto, R.; D'Anna, F.; Prato, M. Nitrogen-Doped Carbon Nanodots-Ionogels: Preparation, Characterization, and Radical Scavenging Activity. ACS Nano 2018, 12, 1296-1305. [CrossRef] [PubMed]

73. Bourlinos, A.B.; Trivizas, G.; Karakassides, M.A.; Baikousi, M.; Kouloumpis, A.; Gournis, D.; Bakandritsos, A.; Hola, K.; Kozak, O.; Zboril, R.; et al. Green and simple route toward boron doped carbon dots with significantly enhanced non-linear optical properties. Carbon 2015, 83, 173-179. [CrossRef]

74. Shan, X.; Chai, L.; Ma, J.; Qian, Z.; Chen, J.; Feng, H. B-doped carbon quantum dots as a sensitive fluorescence probe for hydrogen peroxide and glucose detection. Analyst 2014, 139, 2322-2325. [CrossRef] [PubMed]

75. Hai, X.; Mao, Q.X.; Wang, W.J.; Wang, X.F.; Chen, X.W.; Wang, J.H. An acid-free microwave approach to prepare highly luminescent boron-doped graphene quantum dots for cell imaging. J. Mater. Chem. B 2015, 3, 9109-9114. [CrossRef]

76. Zhang, L.; Zhang, Z.Y.; Liang, R.P.; Li, Y.H.; Qiu, J.D. Boron-Doped Graphene Quantum Dots for Selective Glucose Sensing Based on the "Abnormal” Aggregation-Induced Photoluminescence Enhancement. Anal. Chem. 2014, 86, 4423-4430. [CrossRef] [PubMed]

77. Sarkar, S.; Das, K.; Ghosh, M.; Das, P.K. Amino acid functionalized blue and phosphorous-doped green fluorescent carbon dots as bioimaging probe. RSC Adv. 2015, 5, 65913-65921. [CrossRef]

78. Zhou, J.; Shan, X.; Ma, J.; Gu, Y.; Qian, Z.; Chen, J.; Feng, H. Facile synthesis of P-doped carbon quantum dots with highly efficient photoluminescence. RSC Adv. 2014, 4, 5465-5468. [CrossRef]

79. Holá, K.; Sudolská, M.; Kalytchuk, S.; Nachtigallová, D.; Rogach, A.L.; Otyepka, M.; Zbořil, R. Graphitic Nitrogen Triggers Red Fluorescence in Carbon Dots. ACS Nano 2017, 11, 12402-12410. [CrossRef]

80. Guo, L.; Ge, J.; Liu, W.; Niu, G.; Jia, Q.; Wang, H.; Wang, P. Tunable multicolor carbon dots prepared from well-defined polythiophene derivatives and their emission mechanism. Nanoscale 2016, 8, 729-734. [CrossRef]

81. Yuan, Y.H.; Liu, Z.X.; Li, R.S.; Zou, H.Y.; Lin, M.; Liu, H.; Huang, C.Z. Synthesis of nitrogen-doping carbon dots with different photoluminescence properties by controlling the surface states. Nanoscale 2016, 8, 6770-6776. [CrossRef] [PubMed]

82. Bhattacharyya, S.; Ehrat, F.; Urban, P.; Teves, R.; Wyrwich, R.; Doblinger, M.; Feldmann, J.; Urban, A.S.; Stolarczyk, J.K. Effect of nitrogen atom positioning on the trade-off between emissive and photocatalytic properties of carbon dots. Nat. Commun. 2017, 8, 1401. [CrossRef] [PubMed]

83. Messina, F.; Sciortino, L.; Popescu, R.; Venezia, A.M.; Sciortino, A.; Buscarino, G.; Agnello, S.; Schneider, R.; Gerthsen, D.; Cannas, M.; et al. Fluorescent nitrogen-rich carbon nanodots with an unexpected $\beta-C_{3} N_{4}$ nanocrystalline structure. J. Mater. Chem. C 2016, 4, 2598-2605. [CrossRef]

84. Linehan, K.; Doyle, H. Efficient one-pot synthesis of highly monodisperse carbon quantum dots. RSC Adv. 2014, 4, 18-21. [CrossRef] 
85. Liu, Y.; Wang, P.; Shiral, K.A.F.; LeCroy, G.E.; Maimaiti, H.; Harruff-Miller, B.A.; Lewis, W.K.; Bunker, C.E.; Hou, Z.L.; Sun, Y.P. Enhanced fluorescence properties of carbon dots in polymer films. J. Mater. Chem. C 2016, 4, 6967-6974. [CrossRef] [PubMed]

86. Zheng, H.; Wang, Q.; Long, Y.; Zhang, H.; Huang, X.; Zhu, R. Enhancing the luminescence of carbon dots with a reduction pathway. Chem. Commun. 2011, 47, 10650-10652. [CrossRef] [PubMed]

87. Yang, Z.C.; Wang, M.; Yong, A.M.; Wong, S.Y.; Zhang, X.H.; Tan, H.; Chang, A.Y.; Li, X.; Wang, J. Intrinsically fluorescent carbon dots with tunable emission derived from hydrothermal treatment of glucose in the presence of monopotassium phosphate. Chem. Commun. 2011, 47, 11615-11617. [CrossRef] [PubMed]

88. Schneider, J.; Reckmeier, C.J.; Xiong, Y.; von Seckendorff, M.; Susha, A.S.; Kasák, P.; Rogach, A.L. Molecular Fluorescence in Citric Acid-Based Carbon Dots. J. Phys. Chem. C. 2017, 121, 2014-2022. [CrossRef]

89. Wen, Z.H.; Yin, X.B. Excitation-independent carbon dots, from photoluminescence mechanism to single-color application. RSC Adv. 2016, 6, 27829. [CrossRef]

90. Arcudi, F.; Dordovic, L.; Prato, M. Synthesis, Separation, and characterization of small and highly fluorescent nitrogen-doped carbon nanodots. Angew. Chem. Int. Ed. 2016, 55, 2107-2112. [CrossRef]

91. Das, A.; Gude, V.; Roy, D.; Chatterjee, T.; De, C.K.; Mandal, P.K. On the Molecular Origin of Photoluminescence of Nonblinking Carbon Dot. J. Phys. Chem. C 2017, 121, 9634-9641. [CrossRef]

92. Fuyuno, N.; Kozawa, D.; Miyauchi, Y.; Mouri, S.; Kitaura, R.; Shinohara, H.; Yasuda, T.; Komatsu, N.; Matsuda, K. Drastic Change in Photoluminescence properties of graphene quantum dots by chromatographic separation. Adv. Opt. Mater. 2014, 2, 983-989. [CrossRef]

93. Cayuela, A.; Soriano, M.L.; Valcàrcel, M. Strong luminescence of carbon dots induced by acetone passivation: Efficient sensor for a rapid analysis of two different pollutants. Anal. Chim. Acta 2013, 804, $246-251$. [CrossRef] [PubMed]

94. Cayuela, A.; Soriano, M.L.; Valcàrcel, M. Reusable sensor based on functionalized carbon dots for the detection of silver nanoparticles in cosmetics via inner filter effect. Anal. Chim. Acta 2015, 872, 70-76. [CrossRef] [PubMed]

95. Ding, H.; Zhang, P.; Wang, T.Y.; Kong, J.L.; Xiong, H.M. Nitrogen-doped carbon dots derived from polyvinyl pyrrolidone and their multicolor cell imaging. Nanotechnology 2014, 25, 205804. [CrossRef]

96. Chen, W.; Hu, C.; Yang, Y.; Cui, J.; Liu, Y. Rapid Synthesis of Carbon Dots by Hydrothermal Treatment of Lignin. Materials 2016, 9, 184. [CrossRef]

97. Pan, D.; Zhang, J.; Li, Z.; Wu, M. Hydrothermal route for cutting graphene sheets into blue-luminescent graphene quantum dots. Adv. Mater. 2010, 22, 734-738. [CrossRef]

98. Reineck, P.; Lau, D.W.M.; Wilson, E.R.; Fox, K.; Field, M.R.; Deeleepojananan, C.; Mochalin, V.N.; Gibson, B.C. Effect of Surface Chemistry on the Fluorescence of Detonation Nanodiamonds. ACS Nano 2017, 11, 10924-10934. [CrossRef]

99. Tong, G.; Wang, J.; Wang, R.; Guo, X.; He, L.; Qiu, F.; Wang, G.; Zhu, B.; Zhu, X.; Liu, T. Amorphous carbon dots with high two-photon fluorescence for cellular imaging passivated by hyperbranched poly(amino amine). J. Mater. Chem. B 2015, 3, 700-706. [CrossRef]

100. Margraf, J.T.; Strauss, V.; Guldi, D.M.; Clark, T. The Electronic Structure of Amorphous Carbon Nanodots. J. Phys. Chem. B 2015, 119, 7258-7265. [CrossRef]

101. Peng, H.; Travas-Sejdic, J. Simple Aqueous Solution Route to Luminescent Carbogenic Dots from Carbohydrates. Chem. Mater. 2009, 21, 5563-5565. [CrossRef]

102. Sharma, A.; Gadly, T.; Neogy, S.; Ghosh, S.K.; Kumbhakar, M. Molecular Origin and Self-Assembly of Fluorescent Carbon Nanodots in Polar Solvents. J. Phys. Chem. Lett. 2017, 8, 1044-1052. [CrossRef] [PubMed]

103. Zhang, W.; Shi, L.; Liu, Y.; Meng, X.; Xu, H.; Xu, Y.; Liu, B.; Fang, X.; Li, H.B.; Ding, T. Supramolecular interactions via hydrogen bonding contributing to citric-acid derived carbon dots with high quantum yield and sensitive photoluminescence. RSC Adv. 2017, 7, 20345-20353. [CrossRef]

104. Varisco, M.; Zufferey, D.; Ruggi, A.; Zhang, Y.; Erni, R.; Mamula, O. Synthesis of hydrophilic and hydrophobic carbon quantum dots from waste of wine fermentation. R. Soc. Open Sci. 2017, 4, 170900. [CrossRef] [PubMed]

105. Ding, Y.; Zhang, F.; Xu, J.; Miao, Y.; Yang, Y.; Liu, X.; Xu, B. Synthesis of short-chain passivated carbon quantum dots as the light emitting layer towards electroluminescence. RSC Adv. 2017, 7, 28754. [CrossRef]

106. Liu, H.; Ye, T.; Mao, C. Fluorescent Carbon Nanoparticles Derived from Candle Soot. Angew. Chem. Int. Ed. 2007, 46, 6473-6475. [CrossRef] [PubMed] 
107. Lu, S.; Sui, L.; Liu, J.; Zhu, S.; Chen, A.; Jin, M.; Yang, B. Near-Infrared Photoluminescent Polymer-Carbon Nanodots with Two-Photon Fluorescence. Adv. Mater. 2017, 29, 1603443. [CrossRef] [PubMed]

108. Lu, S.; Xiao, G.; Sui, L.; Feng, T.; Yong, X.; Zhu, S.; Li, B.; Liu, Z.; Zou, B.; Jin, M.; Tse, J.S.; Yan, H.; Yang, B. Piezochromic Carbon Dots with Two-photon Fluorescence. Angew. Chem. Int. Ed. 2017, 56, 6187-6191. [CrossRef] [PubMed]

109. Zhu, Z.; Ma, J.; Wang, Z.; Mu, C.; Fan, Z.; Du, L.; Bai, Y.; Fan, L.; Yan, H.; Phillips, D.L.; Yang, S. Efficiency Enhancement of Perovskite Solar Cells through Fast Electron Extraction: The Role of Graphene Quantum Dots. J. Am. Chem. Soc. 2014, 136, 3760-3763. [CrossRef] [PubMed]

110. Mihalache, I.; Radoi, A.; Mihaila, M.; Munteanu, C.; Marin, A.; Danila, M.; Kusko, M.; Kusko, C. Charge and energy transfer interplay in hybrid sensitized solar cells mediated by graphene quantum dots. Electrochim. Acta 2015, 153, 306-315. [CrossRef]

111. Chen, Q.L.; Wang, C.F.; Chen, S. One-step synthesis of yellow-emitting carbogenic dots toward white light-emitting diodes. J. Mater. Sci. 2012, 48, 2352-2357. [CrossRef]

112. Yang, X.; Zhuo, Y.; Zhu, S.; Luo, Y.; Feng, Y.; Dou, Y. Novel and green synthesis of high-fluorescent carbon dots originated from honey for sensing and imaging. Biosens. Bioelectron. 2014, 60, 292-298. [CrossRef] [PubMed]

113. Zhang, H.; Chen, Y.; Liang, M.; Xu, L.; Qi, S.; Chen, H.; Chen, X. Solid-Phase Synthesis of Highly Fluorescent Nitrogen-Doped Carbon Dots for Sensitive and Selective Probing Ferric Ions in Living Cells. Anal. Chem. 2014, 86, 9846-9852. [CrossRef] [PubMed]

114. Zhang, Y.L.; Wang, L.; Zhang, H.C.; Liu, Y.; Wang, H.Y.; Kang, Z.H.; Lee, S.T. Graphitic carbon quantum dots as a fluorescent sensing platform for highly efficient detection of $\mathrm{Fe}^{3+}$ ions. RSC Adv. 2013, 3, 3733-3738. [CrossRef]

115. Lu, W.; Qin, X.; Liu, S.; Chang, G.; Zhang, Y.; Luo, Y.; Asiri, A.M.; Al-Youbi, A.O.; Sun, X. Economical, Green Synthesis of Fluorescent Carbon Nanoparticles and Their Use as Probes for Sensitive and Selective Detection of Mercury(II) Ions. Anal. Chem. 2012, 84, 5351-5357. [CrossRef] [PubMed]

116. Zhao, H.X.; Liu, L.Q.; Liu, Z.D.; Wang, Y.; Zhao, X.J.; Huang, C.Z. Highly selective detection of phosphate in very complicated matrixes with an off-on fluorescent probe of europium-adjusted carbon dots. Chem. Commun. 2011, 47, 2604-2606. [CrossRef] [PubMed]

117. Hou, X.; Zeng, F.; Du, F.; Wu, S. Carbon-dot-based fluorescent turn-on sensor for selectively detecting sulfide anions in totally aqueous media and imaging inside live cells. Nanotechnology 2013, 24, 335502. [CrossRef] [PubMed]

118. Li, S.; Skromne, I.; Peng, Z.; Dallman, J.; Al-Youbi, A.O.; Bashammakh, A.S.; El-Shahawi, M.S.; Leblanc, R.M. “Dark" carbon dots specifically "light-up" calcified zebrafish bones. J. Mater. Chem. B 2016, 4, 7398-7405. [CrossRef]

119. Tao, H.; Yang, K.; Ma, Z.; Wan, J.; Zhang, Y.; Kang, Z.; Liu, Z. In Vivo NIR Fluorescence Imaging, Biodistribution, and Toxicology of Photoluminescent Carbon Dots Produced from Carbon Nanotubes and Graphite. Small 2012, 8, 281-290. [CrossRef]

120. Zheng, M.; Ruan, S.; Liu, S.; Sun, T.; Qu, D.; Zhao, H.; Xie, Z.; Gao, H.; Jing, X.; Sun, Z. Self-Targeting Fluorescent Carbon Dots for Diagnosis of Brain Cancer Cells. ACS Nano 2015, 9, 11455-11461. [CrossRef]

121. Kang, Y.F.; Li, Y.H.; Fang, Y.W.; Xu, Y.; Wei, X.M.; Yin, X.B. Carbon Quantum Dots for Zebrafish Fluorescence imaging. Sci. Rep. 2015, 5, 11835. [CrossRef] [PubMed]

122. Qu, Z.B.; Zhou, X.; Gu, L.; Lan, R.; Sun, D.; Yu, D.; Shi, G. Boronic acid functionalized graphene quantum dots as a fluorescent probe for selective and sensitive glucose determination in microdialysate. Chem. Commun. 2013, 49, 9830-9832. [CrossRef] [PubMed]

123. Shereema, R.M.; Sruthi, T.V.; Kumar, V.B.S.; Rao, T.P.; Shankar, S.S. Angiogenic Profiling of Synthesized Carbon Quantum Dots. Biochemistry 2015, 54, 6352-6356. [CrossRef]

124. Liu, C.; Zhang, P.; Zhai, X.; Tian, F.; Li, W.; Yang, J.; Liu, Y.; Wang, H.; Wang, W.; Liu, W. Nano-carrier for gene delivery and bioimaging based on carbon dots with PEI-passivation enhanced fluorescence. Biomaterials 2012, 33, 3604-3613. [CrossRef] [PubMed]

125. Xu, J.; Zeng, F.; Wu, H.; Hu, C.; Yu, C.; Wu, S. Preparation of a Mitochondria-targeted and NO-Releasing Nanoplatform and its Enhanced Pro-Apoptotic Effect on Cancer Cells. Small 2014, 10, 3750-3760. [CrossRef] [PubMed] 
126. Pardo, J.; Peng, Z.; Leblanc, R.M. Cancer Targeting and Drug Delivery Using Carbon-Based Quantum Dots and Nanotubes. Molecules 2018, 23, 378. [CrossRef] [PubMed]

127. Dong, X.; Moyer, M.M.; Yang, F.; Sun, Y.P.; Yang, L. Carbon Dots' antiviral functions against noroviruses. Sci. Rep. 2017, 7, 519. [CrossRef]

128. Barras, A.; Pagneux, Q.; Sane, F.; Wang, Q.; Boukherroub, R.; Hober, D.; Szunerits, S. High Efficiency of Functional Carbon Nanodots as Entry Inhibitors of Herpes Simplex Virus Type 1. ACS Appl. Mater. Interfaces 2016, 8, 9004-9013. [CrossRef]

129. Roy, A.K.; Kim, S.M.; Paoprasert, P.; Park, S.Y.; In, I. Preparation of biocompatible and antibacterial carbon quantum dots derived from resorcinol and formaldehyde spheres. RSC Adv. 2015, 5, 31677-31682. [CrossRef]

130. Sultana, N.; Raul, P.K.; Goswami, D.; Das, B.; Gogoi, H.K.; Raju, P.S. Nanoweapon: Control of mosquito breeding using carbon-dot-silver nanohybrid as a biolarvicide. Environ. Chem. Lett. 2018, 16, 1017-1023. [CrossRef]

131. da Silva, J.C.E.; Gonçalves, H.M. Analytical and bioanalytical applications of carbon dots. Trends Anal. Chem. 2011, 30, 1327-1336. [CrossRef]

132. Sciortino, A.; Madonia, A.; Gazzetto, M.; Sciortino, L.; Rohwer, E.J.; Feurer, T.; Gelardi, F.M.; Cannas, M.; Cannizzo, A.; Messina, F. The interaction of photoexcited carbon nanodots with metal ions disclosed down to the femtosecond scale. Nanoscale 2017, 9, 11902-11911. [CrossRef] [PubMed]

133. Zong, J.; Yang, X.; Trinchi, A.; Hardin, S.; Cole, I.; Zhu, Y.; Li, C.; Muster, T.; Wei, G. Carbon dots as fluorescent probes for "off-on" detection of $\mathrm{Cu}^{2+}$ and l-cysteine in aqueous solution. Biosens. Bioelectron. 2014, 51, 330-335. [CrossRef] [PubMed]

134. Zhang, L.; Han, Y.; Zhu, J.; Zhai, Y.; Dong, S. Simple and Sensitive Fluorescent and Electrochemical Trinitrotoluene Sensors Based on Aqueous Carbon Dots. Anal. Chem. 2015, 87, 2033-2036. [CrossRef] [PubMed]

135. Shi, D.; Yan, F.; Zheng, T.; Wang, Y.; Zhou, X.; Chen, L. P-doped carbon dots act as a nanosensor for trace 2,4,6-trinitrophenol detection and a fluorescent reagent for biological imaging. RSC Adv. 2015, 5, 98492-98499. [CrossRef]

136. Li, N.; Than, A.; Chen, J.; Xi, F.; Liu, J.; Chen, P. Graphene quantum dots based fluorescence turn-on nanoprobe for highly sensitive and selective imaging of hydrogen sulfide in living cells. Biomater. Sci. 2018, 6, 779-784. [CrossRef] [PubMed]

137. Campos, B.B.; Contreras-Cáceres, R.; Bandosz, T.J.; Jiménez-Jiménez, J.; Rodríguez-Castellón, E.; da Silva, J.C.E.; Algarra, M. Carbon dots as fluorescent sensor for detection of explosive nitrocompounds. Carbon 2016, 106, 171-178. [CrossRef]

138. Liu, R.; Li, H.; Kong, W.; Liu, J.; Liu, Y.; Tong, C.; Zhang, X.; Kang, Z. Ultra-sensitive and selective $\mathrm{Hg}^{2+}$ detection based on fluorescent carbon dots. Mater. Res. Bull. 2013, 48, 2529-2534. [CrossRef]

139. Liu, C.; Tang, B.; Zhang, S.; Zhou, M.; Yang, M.; Liu, Y.; Zhang, Z.L.; Zhang, B.; Pang, D.W. Photoinduced Electron Transfer Mediated by Coordination between Carboxyl on Carbon Nanodots and $\mathrm{Cu}^{2+}$ Quenching Photoluminescence. J. Phys. Chem. C 2018, 122, 3662-3668. [CrossRef]

140. Hu, S.; Zhao, Q.; Chang, Q.; Yang, J.; Liu, J. Enhanced performance of $\mathrm{Fe}^{3+}$ detection via fluorescence resonance energy transfer between carbon quantum dots and Rhodamine B. RSC Adv. 2014, 4, 41069-41075. [CrossRef]

141. Wang, Y.; Jiang, K.; Zhu, J.; Zhang, L.; Lin, H. A FRET-based carbon dot-MnO $\mathrm{M}_{2}$ nanosheet architecture for glutathione sensing in human whole blood samples. Chem. Commun. 2015, 51, 12748-12751. [CrossRef] [PubMed]

142. Hu, Y.; Yang, J.; Jia, L.; Yu, J.S. Ethanol in aqueous hydrogen peroxide solution: Hydrothermal synthesis of highly photoluminescent carbon dots as multifunctional nanosensors. Carbon 2015, 93, 999-1007. [CrossRef]

143. Sun, X.; Lei, Y. Fluorescent carbon dots and their sensing applications. Trends Anal. Chem. 2017, 89, 163-180. [CrossRef]

144. Chandra, S.; Patra, P.; Pathan, S.H.; Roy, S.; Mitra, S.; Layek, A.; Bhar, R.; Pramanik, P.; Goswami, A. Luminescent S-doped carbon dots: An emergent architecture for multimodal applications. J. Mater. Chem. B 2013, 1, 2375-2382. [CrossRef]

145. Zhao, D.; Chen, C.; Lu, L.; Yang, F.; Yang, X. A dual-mode colorimetric and fluorometric "light on" sensor for thiocyanate based on fluorescent carbon dots and unmodified gold nanoparticles. Analyst 2015, 140, 8157-8164. [CrossRef] [PubMed] 
146. Qu, Q.; Zhu, A.; Shao, X.; Shi, G.; Tian, Y. Development of a carbon quantum dots-based fluorescent $\mathrm{Cu}^{2+}$ probe suitable for living cell imaging. Chem. Commun. 2012, 48, 5473-5475. [CrossRef] [PubMed]

147. Lin, X.; Gao, G.; Zheng, L.; Chi, Y.; Chen, G. Encapsulation of Strongly Fluorescent Carbon Quantum Dots in Metal-Organic Frameworks for Enhancing Chemical Sensing. Anal. Chem. 2014, 86, 1223-1228. [CrossRef]

148. Mohapatra, S.; Sahu, S.; Nayak, S.; Ghosh, S.K. Design of $\mathrm{Fe}_{3} \mathrm{O}_{4} @ \mathrm{SiO}_{2} @$ Carbon Quantum Dot Based Nanostructure for Fluorescence Sensing, Magnetic Separation, and Live Cell Imaging of Fluoride Ion. Langmuir 2015, 31, 8111-8120. [CrossRef]

149. Wang, X.; Zhang, J.; Zou, W.; Wang, R. Facile synthesis of polyaniline/carbon dot nanocomposites and their application as a fluorescent probe to detect mercury. RSC Adv. 2015, 5, 41914-41919. [CrossRef]

150. Zhu, A.; Qu, Q.; Shao, X.; Kong, B.; Tian, Y. Carbon-Dot-Based Dual-Emission Nanohybrid Produces a Ratiometric Fluorescent Sensor for In Vivo Imaging of Cellular Copper Ions. Angew. Chem. Int. Ed. 2012, 51, 7185-7189. [CrossRef]

151. Qu, S.; Chen, H.; Zheng, X.; Cao, J.; Liu, X. Ratiometric fluorescent nanosensor based on water soluble carbon nanodots with multiple sensing capacities. Nanoscale 2013, 5, 5514-5518. [CrossRef] [PubMed]

152. Zhang, W.F.; Zhu, H.; Yu, S.F.; Yang, H.Y. Observation of Lasing Emission from Carbon Nanodots in Organic Solvents. Adv. Mater. 2012, 24, 2263-2267. [CrossRef] [PubMed]

153. Zhu, H.; Zhang, W.; Yu, S.F. Realization of lasing emission from graphene quantum dots using titanium dioxide nanoparticles as light scatterers. Nanoscale 2013, 5, 1797-1802. [CrossRef]

154. Zhang, W.; Ni, Y.; Xu, X.; Lu, W.; Ren, P.; Yan, P.; Siu, C.K.; Ruan, S.; Yu, S.F. Realization of multiphoton lasing from carbon nanodot microcavities. Nanoscale 2017, 9, 5957-5963. [CrossRef]

155. Margraf, J.T.; Lodermeyer, F.; Strauss, V.; Haines, P.; Walter, J.; Peukert, W.; Costa, R.D.; Clark, T.; Guldi, D.M. Using carbon nanodots as inexpensive and environmentally friendly sensitizers in mesoscopic solar cells. Nanoscale Horiz. 2016, 1, 220-226. [CrossRef]

156. Hutton, G.A.M.; Martindale, B.C.M.; Reisner, E. Carbon dots as photosensitisers for solar-driven catalysis. Chem. Soc. Rev. 2017, 46, 6111-6123. [CrossRef] [PubMed]

157. Xie, S.; Su, H.; Wei, W.; Li, M.; Tong, Y.; Mao, Z. Remarkable photoelectrochemical performance of carbon dots sensitized $\mathrm{TiO}_{2}$ under visible light irradiation. J. Mater. Chem. A 2014, 2, 16365-16368. [CrossRef]

158. Zhang, H.; Ming, H.; Lian, S.; Huang, H.; Li, H.; Zhang, L.; Liu, Y.; Kang, Z.; Lee, S.T. Fe $\mathrm{O}_{3}$ / carbon quantum dots complex photocatalysts and their enhanced photocatalytic activity under visible light. Dalton Trans. 2011, 40, 10822-10825. [CrossRef]

159. Cao, L.; Sahu, S.; Anilkumar, P.; Bunker, C.E.; Xu, J.; Fernando, K.A.S.; Wang, P.; Guliants, E.A.; Tackett, K.N.; Sun, Y.P. Carbon Nanoparticles as Visible-Light Photocatalysts for Efficient $\mathrm{CO}_{2}$ Conversion and Beyond. J. Am. Chem. Soc. 2011, 133, 4754-4757. [CrossRef]

160. Mehta, A.; Pooja, D.; Thakur, A.; Basu, S. Enhanced photocatalytic water splitting by gold carbon dot core shell nanocatalyst under visible/sunlight. New J. Chem. 2017, 41, 4573-4581. [CrossRef]

161. Song, Y.; Zhu, S.; Zhang, S.; Fu, Y.; Wang, L.; Zhao, X.; Yang, B. Investigation from chemical structure to photoluminescent mechanism: A type of carbon dots from the pyrolysis of citric acid and an amine. J. Mater. Chem. C 2015, 3, 5976-5984. [CrossRef]

162. Klimov, V.I. Spectral and dynamical properties of multiexcitons in semiconductor nanocrystals. Annu. Rev. Phys. Chem. 2008, 58, 635-673. [CrossRef] [PubMed]

163. Li, L.S.; Yan, X. Colloidal Graphene Quantum Dots. J. Phys. Chem. Lett. 2010, 1, 2572-2576. [CrossRef]

164. Mueller, M.L.; Yan, X.; Dragnea, B.; Li, L.S. Slow Hot-Carrier Relaxation in Colloidal Graphene Quantum Dots. Nano Lett. 2011, 11, 56-60. [CrossRef] [PubMed]

165. Cao, L.; Meziani, M.J.; Sahu, S.; Sun, Y.P. Photoluminescence Properties of Graphene versus Other Carbon Nanomaterials. Acc. Chem. Res. 2013, 46, 171-180. [CrossRef] [PubMed]

166. Zhu, S.; Wang, L.; Bo, L.; Song, Y.; Zhao, X.; Zhang, G.; Zhang, S.; Lu, S.; Zhang, J.; Wang, H.; et al. Investigation of photoluminescence mechanism of graphene quantum dots and evaluation of their assembly into polymer dots. Carbon 2014, 77, 462-472. [CrossRef]

167. Sk, M.A.; Ananthanarayanan, A.; Huang, L.; Lim, K.H.; Chen, P. Revealing the tunable photoluminescence properties of graphene quantum dots. J. Mater. Chem. C 2014, 2, 6954-6960. [CrossRef]

168. Eda, G.; Lin, Y.Y.; Mattevi, C.; Yamaguchi, H.; Chen, H.A.; Chen, I.S.; Chen, C.W.; Chhowalla, M. Blue Photoluminescence from Chemically Derived Graphene Oxide. Adv. Mater. 2010, 22, 505-509. [CrossRef] 
169. Peng, J.; Gao, W.; Gupta, B.K.; Liu, Z.; Romero-Aburto, R.; Ge, L.; Song, L.; Alemany, L.B.; Zhan, X.; Gao, G.; et al. Graphene Quantum Dots Derived from Carbon Fibers. Nano Lett. 2012, 12, 844-849. [CrossRef]

170. Yuan, F.; Yuan, T.; Sui, L.; Wang, Z.; Xi, Z.; Li, Y.; Li, X.; Fan, L.; Tan, Z.; Chen, A.; et al. Engineering triangular carbon quantum dots with unprecedented narrow bandwidth emission for multicolored LEDs. Nat. Commun. 2018, 9, 2249. [CrossRef]

171. Ye, R.; Xiang, C.; Lin, J.; Peng, Z.; Huang, K.; Yan, Z.; Cook, N.P.; Samuel, E.L.G.; Hwang, C.C.; Ruan, G.; et al. Coal as an abundant source of graphene quantum dots. Nat. Commun. 2013, 4, 2943. [CrossRef] [PubMed]

172. Gokus, T.; Nair, R.R.; Bonetti, A.; Böhmler, M.; Lombardo, A.; Novoselov, K.S.; Geim, A.K.; Ferrari, A.C.; Hartschuh, A. Making Graphene Luminescent by Oxygen Plasma Treatment. ACS Nano 2009, 3, 3963-3968. [CrossRef] [PubMed]

173. Sciortino, A.; Gazzetto, M.; Buscarino, G.; Popescu, R.; Schneider, R.; Giammona, G.; Gerthsen, D.; Rohwer, E.J.; Mauro, N.; Feurer, T.; et al. Disentangling size effects and spectral inhomogeneity in carbon nanodots by ultrafast dynamical hole-burning. Nanoscale 2018, 10, 15317-15323. [CrossRef] [PubMed]

174. Yu, P.; Wen, X.; Toh, Y.R.; Tang, J. Temperature-Dependent Fluorescence in Carbon Dots. J. Phys. Chem. C 2012, 116, 25552-25557. [CrossRef]

175. Chandra, S.; Pathan, S.H.; Mitra, S.; Modha, B.H.; Goswami, A.; Pramanik, P. Tuning of photoluminescence on different surface functionalized carbon quantum dots. RSC Adv. 2012, 2, 3602-3606. [CrossRef]

176. Zhu, S.; Zhang, J.; Liu, X.; Li, B.; Wang, X.; Tang, S.; Meng, Q.; Li, Y.; Shi, C.; Hu, R.; et al. Graphene quantum dots with controllable surface oxidation, tunable fluorescence and up-conversion emission. RSC Adv. 2012, 2, 2717-2720. [CrossRef]

177. Ding, H.; Yu, S.B.; Wei, J.S.; Xiong, H.M. Full-Color Light-Emitting Carbon Dots with a Surface-State-Controlled Luminescence Mechanism. ACS Nano 2016, 10, 484-491. [CrossRef] [PubMed]

178. Wang, L.; Zhu, S.J.; Wang, H.Y.; Qu, S.N.; Zhang, Y.L.; Zhang, J.H.; Chen, Q.D.; Xu, H.L.; Han, W.; Yang, B.; et al. Common Origin of Green Luminescence in Carbon Nanodots and Graphene Quantum Dots. ACS Nano 2014, 8, 2541-2547. [CrossRef] [PubMed]

179. Strauss, V.; Kahnt, A.; Zolnhofer, E.M.; Meyer, K.; Maid, H.; Placht, C.; Bauer, W.; Nacken, T.J.; Peukert, W.; Etschel, S.H.; et al. Assigning Electronic States in Carbon Nanodots. Adv. Funct. Mater. 2016, 26, 7975-7985. [CrossRef]

180. Khan, S.; Gupta, A.; Verma, N.C.; Nandi, C.K. Time-Resolved Emission Reveals Ensemble of Emissive States as the Origin of Multicolor Fluorescence in Carbon Dots. Nano Lett. 2015, 15, 8300-8305. [CrossRef] [PubMed]

181. Kumar, P.; Bohidar, H. Observation of fluorescence from non-functionalized carbon nanoparticles and its solvent dependent spectroscopy. J. Lumin. 2013, 141, 155-161. [CrossRef]

182. Shi, L.; Yang, J.H.; Zeng, H.B.; Chen, Y.M.; Yang, S.C.; Wu, C.; Zeng, H.; Yoshihito, O.; Zhang, Q. Carbon dots with high fluorescence quantum yield: The fluorescence originates from organic fluorophores. Nanoscale 2016, 8, 14374-14378. [CrossRef] [PubMed]

183. Wang, W.; Wang, B.; Embrechts, H.; Damm, C.; Cadranel, A.; Strauss, V.; Distaso, M.; Hinterberger, V.; Guldi, D.M.; Peukert, W. Shedding light on the effective fluorophore structure of high fluorescence quantum yield carbon nanodots. RSC Adv. 2017, 7, 24771-24780. [CrossRef]

184. Reckmeier, C.J.; Schneider, J.; Xiong, Y.; Häusler, J.; Kasák, P.; Schnick, W.; Rogach, A.L. Aggregated Molecular Fluorophores in the Ammonothermal Synthesis of Carbon Dots. Chem. Mater. 2017, 29, 10352-10361. [CrossRef]

185. Righetto, M.; Privitera, A.; Fortunati, I.; Mosconi, D.; Zerbetto, M.; Curri, M.L.; Corricelli, M.; Moretto, A.; Agnoli, S.; Franco, L.; et al. Spectroscopic Insights into Carbon Dot Systems. J. Phys. Chem. Lett. 2017, 8, 2236-2242. [CrossRef] [PubMed]

186. Liu, X.; Li, H.B.; Shi, L.; Meng, X.; Wang, Y.; Chen, X.; Xu, H.; Zhang, W.; Fang, X.; Ding, T. Structure and photoluminescence evolution of nanodots during pyrolysis of citric acid: From molecular nanoclusters to carbogenic nanoparticles. J. Mater. Chem. C 2017, 5, 10302-10312. [CrossRef]

187. Krysmann, M.J.; Kelarakis, A.; Dallas, P.; Giannelis, E.P. Formation Mechanism of Carbogenic Nanoparticles with Dual Photoluminescence Emission. J. Am. Chem. Soc. 2012, 134, 747-750. [CrossRef] [PubMed]

188. Kasprzyk, W.; Bednarz, S.; Zmudzki, P.; Galica, M.; Bogdal, D. Novel efficient fluorophores synthesized from citric acid. RSC Adv. 2015, 5, 34795-34799. [CrossRef] 
189. Demchenko, A.P.; Dekaliuk, M.O. The origin of emissive states of carbon nanoparticles derived from ensemble-averaged and single-molecular studies. Nanoscale 2016, 8, 14057-14069. [CrossRef]

190. Khan, S.; Verma, N.C.; Chethana, R.; Nandi, C.K. Carbon Dots for Single-Molecule Imaging of the Nucleolus. ACS Appl. Nano Mater. 2018, 1, 483-487. [CrossRef]

191. Ghosh, S.; Chizhik, A.M.; Karedla, N.; Dekaliuk, M.O.; Gregor, I.; Schuhmann, H.; Seibt, M.; Bodensiek, K.; Schaap, I.A.T.; Schulz, O.; et al. Photoluminescence of Carbon Nanodots: Dipole Emission Centers and Electron-Phonon Coupling. Nano Lett. 2014, 14, 5656-5661. [CrossRef] [PubMed]

192. Das, S.K.; Liu, Y.; Yeom, S.; Kim, D.Y.; Richards, C.I. Single-Particle Fluorescence Intensity Fluctuations of Carbon Nanodots. Nano Lett. 2014, 14, 620-625. [CrossRef] [PubMed]

193. Sharma, A.; Gadly, T.; Gupta, A.; Ballal, A.; Ghosh, S.K.; Kumbhakar, M. Origin of Excitation Dependent Fluorescence in Carbon Nanodots. J. Phys. Chem. Lett. 2016, 7, 3695-3702. [CrossRef] [PubMed]

194. van Dam, B.; Nie, H.; Ju, B.; Marino, E.; Paulusse, J.M.J.; Schall, P.; Li, M.; Dohnalová, K. Excitation-Dependent Photoluminescence from Single-Carbon Dots. Small 2017, 13, 1702098. [CrossRef] [PubMed]

195. Lin, H.; Hania, R.P.; Bloem, R.; Mirzov, O.; Thomsson, D.; Scheblykin, I.G. Single chain versus single aggregate spectroscopy of conjugated polymers. Where is the border? Phys. Chem. Chem. Phys. 2010, 12, 11770-11777. [CrossRef] [PubMed]

196. Ehrat, F.; Bhattacharyya, S.; Schneider, J.; Löf, A.; Wyrwich, R.; Rogach, A.L.; Stolarczyk, J.K.; Urban, A.S.; Feldmann, J. Tracking the Source of Carbon Dot Photoluminescence: Aromatic Domains versus Molecular Fluorophores. Nano Lett. 2017, 17, 7710-7716. [CrossRef] [PubMed]

197. Wang, X.; Cao, L.; Lu, F.; Meziani, M.J.; Li, H.; Qi, G.; Zhou, B.; Harruff, B.A.; Kermarrec, F.; Sun, Y.P. Photoinduced electron transfers with carbon dots. Chem. Commun. 2009, 25, 3774-3776. [CrossRef] [PubMed]

198. Qian, Z.; Ma, J.; Shan, X.; Feng, H.; Shao, L.; Chen, J. Highly Luminescent N-Doped Carbon Quantum Dots as an Effective Multifunctional Fluorescence Sensing Platform. Chem. Eur. J. 2014, 20, 2254-2263. [CrossRef] [PubMed]

199. Wang, J.C.; Violette, K.; Ogunsolu, O.O.; Hanson, K. Metal ion mediated electron transfer at dye-semiconductor interfaces. Phys. Chem. Chem. Phys. 2017, 19, 2679-2682. [CrossRef] [PubMed]

200. Mondal, S.; Das, T.; Ghosh, P.; Maity, A.; Mallick, A.; Purkayastha, P. Surfactant chain length controls photoinduced electron transfer in surfactant bilayer protected carbon nanoparticles. Mater. Lett. 2015, 141, 252-254. [CrossRef]

201. Martindale, B.C.M.; Hutton, G.A.M.; Caputo, C.A.; Prantl, S.; Godin, R.; Durrant, J.R.; Reisner, E. Enhancing Light Absorption and Charge Transfer Efficiency in Carbon Dots through Graphitization and Core Nitrogen Doping. Angew. Chem. Int. Ed. 2017, 56, 6459-6463. [CrossRef] [PubMed]

202. Wei, W.; Xu, C.; Ren, J.; Xu, B.; Qu, X. Sensing metal ions with ion selectivity of a crown ether and fluorescence resonance energy transfer between carbon dots and graphene. Chem. Commun. 2012, 48, 1284-1286. [CrossRef] [PubMed]

203. Yuan, C.; Liu, B.; Liu, F.; Han, M.Y.; Zhang, Z. Fluorescent “Turn on" detection of mercuric ion based on Bis(sithiocarbamato)copper(II) Complex Fnctionalized Carbon Nanodots. Anal. Chem. 2014, 86, 1123-1130. [CrossRef] [PubMed]

204. Mondal, S.; Seth, S.K.; Gupta, P.; Purkayastha, P. Ultrafast Photoinduced Electron Transfer between Carbon Nanoparticles and Cyclometalated Rhodium and Iridium Complexes. J. Phys. Chem. C 2015, 119, 25122-25128. [CrossRef]

205. Rigodanza, F.; Dordevic, L.; Arcudi, F.; Prato, M. Customizing the electrochemical properties of carbon nanodots by using quinones in bottom up synthesis. Angew. Chem. Int. Ed. 2018, 130, 5156-5161. [CrossRef]

206. Barman, M.K.; Jana, B.; Bhattacharyya, S.; Patra, A. Photophysical Properties of Doped Carbon Dots (N, P, and B) and Their Influence on Electron/Hole Transfer in Carbon Dots-Nickel (II) Phthalocyanine Conjugates. J. Phys. Chem. C 2014, 118, 20034-20041. [CrossRef]

207. Jing, P.; Han, D.; Li, D.; Zhou, D.; Zhang, L.; Zhang, H.; Shen, D.; Qu, S. Origin of Anisotropic Photoluminescence in Heteroatom-Doped Carbon Nanodots. Adv. Opt. Mater. 2017, 5, 1601049. [CrossRef]

208. Mukherjee, S.; Prasad, E.; Chadha, A. H-Bonding controls the emission properties of functionalized carbon nano-dots. Phys. Chem. Chem. Phys. 2017, 19, 7288-7296. [CrossRef] 
209. Pramanik, A.; Biswas, S.; Kumbhakar, P. Solvatochromism in highly luminescent environmental friendly carbon quantum dots for sensing applications: Conversion of bio-waste into bio-asset. Spectrochim. Acta Part A 2018, 191, 498-512. [CrossRef]

210. Song, Y.; Zhu, S.; Xiang, S.; Zhao, X.; Zhang, J.; Zhang, H.; Fu, Y.; Yang, B. Investigation into the fluorescence quenching behaviors and applications of carbon dots. Nanoscale 2014, 6, 4676-4682. [CrossRef]

211. Jones, S.S.; Sahatiya, P.; Badhulika, S. One step, high yield synthesis of amphiphilic carbon quantum dots derived from chia seeds: A solvatochromic study. New J. Chem. 2017, 41, 13130-13139. [CrossRef]

212. van Stokkum, I.H.M.; Larsen, D.S.; van Grondelle, R. Global and target analysis of time-resolved spectra. Biochim. Biophys. Acta 2004, 1657, 82-104. [CrossRef] [PubMed]

213. Tetsuka, H.; Nagoya, A.; Fukusumi, T.; Matsui, T. Molecularly Designed, Nitrogen-Functionalized Graphene Quantum Dots for Optoelectronic Devices. Adv. Mater. 2016, 28, 4632-4638. [CrossRef] [PubMed]

214. Wang, L.; Zhu, S.J.; Wang, H.Y.; Wang, Y.F.; Hao, Y.W.; Zhang, J.H.; Chen, Q.D.; Zhang, Y.L.; Han, W.; Yang, B.; et al. Unraveling Bright Molecule-Like State and Dark Intrinsic State in Green-Fluorescence Graphene Quantum Dots via Ultrafast Spectroscopy. Adv. Opt. Mater. 2013, 1, 264-271. [CrossRef]

215. Wen, X.; Yu, P.; Toh, Y.R.; Hao, X.; Tang, J. Intrinsic and Extrinsic Fluorescence in Carbon Nanodots: Ultrafast Time-Resolved Fluorescence and Carrier Dynamics. Adv. Opt. Mater. 2013, 1, 173-178. [CrossRef]

216. Yu, P.; Wen, X.; Toh, Y.R.; Lee, Y.C.; Huang, K.Y.; Huang, S.; Shrestha, S.; Conibeer, G.; Tang, J. Efficient electron transfer in carbon nanodot-graphene oxide nanocomposites. J. Mater. Chem. C 2014, 2, $2894-2901$. [CrossRef]

217. Williams, K.J.; Nelson, C.A.; Yan, X.; Li, L.S.; Zhu, X. Hot Electron Injection from Graphene Quantum Dots to $\mathrm{TiO}_{2}$. ACS Nano 2013, 7, 1388-1394. [CrossRef]

218. Strauss, V.; Margraf, J.T.; Dirian, K.; Syrgiannis, Z.; Prato, M.; Wessendorf, C.; Hirsch, A.; Clark, T.; Guldi, D.M. Carbon Nanodots: Supramolecular Electron Donor-Acceptor Hybrids Featuring Perylenediimides. Angew. Chem. Int. Ed. 2015, 54, 8292-8297. [CrossRef]

219. Hasenohrl, D.H.; Saha, A.; Strauss, V.; Wibmer, L.; Klein, S.; Guldi, D.M.; Hirsch, A. Bulbous gold-carbon nanodot hybrid nanoclusters for cancer therapy. J. Mater. Chem. B 2017, 5, 8591-8599. [CrossRef]

(C) 2018 by the authors. Licensee MDPI, Basel, Switzerland. This article is an open access article distributed under the terms and conditions of the Creative Commons Attribution (CC BY) license (http:/ / creativecommons.org/licenses/by/4.0/). 